Article

\title{
An Energy Model for the Calculation of Room Acoustic Parameters in Rectangular Rooms with Absorbent Ceilings
}

\author{
Erling Nilsson ${ }^{1, *(D)}$ and Emma Arvidsson ${ }^{2}$ (D) \\ 1 Saint-Gobain Ecophon AB, Yttervägen 1, 26575 Hyllinge, Sweden \\ 2 Engineering Acoustics, Lund University, John Ericssons väg 1, 22100 Lund, Sweden; \\ emma.arvidsson@construction.lth.se \\ * Correspondence: erling.nilsson@ecophon.se
}

Citation: Nilsson, E.; Arvidsson, E. An Energy Model for the Calculation of Room Acoustic Parameters in Rectangular Rooms with Absorbent Ceilings. Appl. Sci. 2021, 11, 6607. https://doi.org/10.3390/app11146607

Academic Editors: Nikolaos M Papadakis, Massimo Garai and Stavroulakis Georgios

Received: 27 June 2021

Accepted: 15 July 2021

Published: 18 July 2021

Publisher's Note: MDPI stays neutral with regard to jurisdictional claims in published maps and institutional affiliations.

Copyright: (c) 2021 by the authors. Licensee MDPI, Basel, Switzerland. This article is an open access article distributed under the terms and conditions of the Creative Commons Attribution (CC BY) license (https:/ / creativecommons.org/licenses/by/ $4.0 /)$.

\begin{abstract}
The most common acoustical treatment of public rooms, such as schools, offices, and healthcare premises, is a suspended absorbent ceiling. The non-uniform distribution of the absorbent material, as well as the influence of sound-scattering objects such as furniture or other interior equipment, has to be taken into account when calculating room acoustic parameters. This requires additional information than what is already inherent in the statistical absorption coefficients and equivalent absorption areas provided by the reverberation chamber method ISO 354 . Furthermore, the classical diffuse field assumption cannot be expected to be valid in these types of rooms. The non-isotropic sound field has to be considered. In this paper, a statistical energy analysis (SEA) model is derived. The sound field is subdivided into a grazing and non-grazing part where the grazing part refers to waves propagating almost parallel to the suspended ceiling. For estimation of all the inherent parameters in the model, the surface impedance of the suspended ceiling has to be known. A method for estimating the scattering and absorbing effects of furniture and objects is suggested in this paper. The room acoustical parameters reverberation time $T_{20}$, speech clarity $C_{50}$, and sound strength $G$ were calculated with the model and compared with calculations according to the classical diffuse field model. Comparison with measurements were performed for a classroom configuration. With regard to all cases, the new model agrees better with measurements than the classical one.
\end{abstract}

Keywords: room acoustics; calculation models; absorption; scattering; airflow resistivity

\section{Introduction}

Many people spend most of their working hours in rooms such as offices, and education and healthcare premises. For the wellbeing of the people in those work places, the acoustical conditions are an important factor. The most common acoustical treatment in these type of public rooms is a suspended absorbent ceiling. The acoustical design is often aimed at reducing noise levels, improving speech intelligibility or, as in open-plan offices, preventing sound propagation. Due to the fact that most of the sound absorption located at the ceiling and other surfaces can be quite sound reflecting, the decay of sound energy and its relation to absorption is not properly explained by the classical assumption of a linear decay under diffuse field condition. These room types comprise a group of rooms where the diffuse field assumption is not valid and the sole use of reverberation time for characterization of the acoustical conditions is not sufficient.

The aim of this paper is to present a model for calculation of reverberation time $T_{20}$, speech clarity $C_{50}$, and sound strength $G$, as defined in ISO 3382-1 [1] and ISO 3382-2 [2]. The model was particularly designed for rooms with suspended absorbent ceilings. For public rooms, such as classrooms, offices, health-care premises, dining rooms, sport arenas, retail premises and similar kind of spaces, the typical acoustical treatment is a suspended absorbent ceiling. The model presented is based on a statistical energy analysis (SEA) approach used to describe the conditions at steady state and during the sound decay. 
Rooms, as mentioned above, are places where large numbers of people spend most of their time during the day. It is obvious that the environment where we spend so many of our working hours should contribute to well-being and the ability to perform working tasks in the best possible way. The acoustical conditions are important in this respect. The purpose of the model presented in this paper is to obtain an estimation of room acoustic parameters for a relevant characterization of the acoustical conditions.

Schools are one of our largest work places. For learning and for the well-being of students and staff in educational premises, acoustic conditions play a central part. It has been recognized in several studies [3-6] that learning and the ability to remember and concentrate are affected by acoustic conditions as well are general well-being and the onset of stress-related symptoms. The effect of different signal-to-noise ratios on the ability to recall words shows that noisy surroundings in classrooms impair learning [7-9].

The effect of room acoustic improvement on the work situation in schools has been investigated in $[10,11]$. It has been shown that, with improved room acoustic conditions, the students social behavior becomes calmer and the teachers experience less physiological load (heart rate) as well as less fatigue. Poor acoustics in classrooms can result in high vocal loading of teachers, which presents a risk factor for voice disorders [12]. Keeping speakers' acoustics conditions in mind, measurement methods for the prediction of voice support and room gain in classrooms have been developed $[13,14]$.

The high activity-based noise levels in preschools have been thoroughly investigated $[15,16]$. However, the long-term effects on children and staff are still a topic for investigations [17].

The sound environment in hospitals is diverse due to different activities that take place, the sound of medical equipment, and alarms and background noise. This can contribute to stress symptoms among staff as well as being a hinderance to patient recovery [18].

The acoustically challenging environments that open-plan spaces involve have received a great deal of attention in recent years [19]. Standards have been developed that present new measurement methods relevant for the typical scenarios occurring in open-plan offices as well as guidelines for creating good acoustic quality in these environments [20,21].

The knowhow relating to characterization of the acoustical conditions in public rooms has increased in recent years. Several investigations [22-25] have pointed out the necessity of addressing several acoustic parameters to achieve a relevant characterization of the acoustic environment. As has been shown, parameters relating to noise levels and speech intelligibility are an important complement to reverberation time. In [26], the speech clarity parameter $U_{50}$, i.e., $C_{50}$, including the effect of background noise, is used for designing good speech conditions in classrooms.

In $[27,28]$, Barron presents a model for calculating clarity index and sound strength in rooms assuming linear sound decay. In [29], special effort was focused on explaining the non-diffusivity effect of the sound fields in public rooms with ceiling treatment and how these circumstances influence these parameters.

Since Sabine's [30] discovery and his classical formula, reverberation time has been the key parameter in room acoustics. In many standards and regulations, it is still the main parameter defining target values for good acoustics [31]. However, today, there are some new standards that have included measures, such as $C_{50}$ and speech transmission index STI [32], as complements to reverberation time [33].

The idea of two rooms with approximately the same reverberation times being perceived as different is not a new finding and is mentioned in textbooks on acoustics $[34,35]$ as well. This is especially the case in public rooms with ceiling treatment.

Many suggestions for improvement of the reverberation time formulas have been made. Several examples of such refinements are given in [34,35].

The influence of different corrections to Sabine's formula has been investigated by Joyce [36,37]. In support of Sabine's formula, Joyce shows that understated conditions of weak absorption and irregular reflections provides the correct answer. 
In [38] Fitzroy presents an empirically derived formula for the reverberation time in rooms with non-uniform distribution of absorption. A modified version of Fitzroy's formula is presented by Neubauer [39]. The non-uniform distribution of absorption is also dealt with by the formula of Arau-Puchades [40]. The effect of location of absorbent material in a mock-up of a classroom and in a reverberation chamber has recently been studied by Cuchrero et al. [41].

In [42], Sakuma uses an image source method where the image sources are grouped as axial, tangential, and oblique groups corresponding to normal modes in wave acoustics. Scattering is taken into account by introducing the scattering coefficient. The non-linear decay in rooms with non-uniform distribution of absorption as well as the importance of scattering are apparent in the results.

In [43], Bistafa and Bradley compared experimental results with analytical and computer predictions of reverberation time in a simulated classroom. Their paper emphasizes the need to quantify the amount of scattering due to furniture and other objects in a room. The influence of scattering is also experimentally investigated by Prodi et al. [44].

A general problem in many reverberation time formulas is the use of a random absorption coefficients as input data. This is of course natural, as most manufacturers of absorbent products provide this data measured according to ISO 354 [45]. However, the non-isotropic properties in rooms with ceiling treatment differ from the almost diffuse conditions in reverberation chambers. In fact, even in reverberation chambers, the concept of a diffuse sound field is hard to achieve [46]. In [47,48], Nilsson presented a model particularly developed for rooms with suspended absorbent ceilings. The non-diffuse conditions were dealt with by introducing two sound fields related to grazing and nongrazing sound waves. The idea of subdividing the sound field into a grazing and nongrazing group were also adopted in [49].

To deal with the non-diffuse conditions in the model presented in this paper, an estimation of the surface impedance of the ceiling is used. The reason is to take into account the angle-dependent properties of the ceiling absorber. This is a major difference to the other energy models referred to above. Another difference to the referred models is the handling of the scattering effect of interior objects such as furniture. In rooms with absorbent ceiling treatments, the directional scattering effect of objects is important. A method for estimation of the directional scattering effect is suggested as an outcome of the model formulation.

When evaluating the reverberation $T_{20}$ or $T_{30}$ according to ISO 3382-2 [2], the dynamical ranges -5 to $-25 \mathrm{~dB}$ and -5 to $-35 \mathrm{~dB}$ are used, respectively. This means that the early reflections of the impulse response are neglected. Therefore, $T_{20}$ and $T_{30}$ are often referred to as late reverberation times. In a room with absorbent ceiling treatment, the late reverberation times are often related to energy travelling in the horizontal plane, comprising grazing waves in relation to the absorbent ceiling.

The importance of early reflections for design of auditoria was already observed by Lochner and Burger [50]. Chiara et al. [51] has investigated the subjective influence of early diffuse reflections on speech intelligibility and spatial perception. In [52], Bradley et al. show the importance of early reflections for speech intelligibility both for normal- and hearing-impaired listeners. These investigations show the benefits of using parameters incorporating the early reflections such as speech clarity.

The examples in the text above show that public rooms with acoustic ceiling treatment comprise a large and important group of rooms that deserve closer examination. This involves investigation into how different acoustical treatment affects the sound field and how this impact can be predicted in a more accurate way than by the classical diffuse field assumption. Further, elucidate the limitations related to only using reverberation time as a descriptor characterising the acoustics.

This paper presents a model that considers the special features of rooms with ceiling treatment and gives an estimation of several room acoustic parameters that are important for the subjective perception of the acoustics. The model takes into account the mounting 
height of ceiling absorbers and absorbent wall panels, as well as the scattering effect of furnishing, diffusers, or other objects. The purpose is to serve the user with a model that gives an estimation of room acoustic parameters that are reasonably consistent with measurements in rooms with ceiling treatment and thus, also to emphasize phenomena that influence the subjective perception of the acoustics.

\section{General Description of the Model}

A general discussion of the model is presented in this chapter. The model is based on a statistical energy analysis (SEA) approach [53,54]. The model addresses rectangular rooms with absorbent ceilings, i.e., rooms where the main contribution to the total absorption is related to the ceiling. A more precise requirement for this condition is given further on.

Important considerations are, firstly, that the surface impedance of the absorbent ceiling, including the air cavity behind the absorber, has to be known, and secondly, that the absorbing and scattering effects of furniture and other interior fittings have to be estimated. A method for measuring the scattering effect is proposed in Section 3.2.5. This method takes into account the directional scattering of objects due to the orientation towards the ceiling.

With the exception of the ceiling, other surfaces in the room are characterized by the statistical absorption coefficient. Further, added wall panels are defined by their statistical absorption coefficient, as measured according to ISO 354 [45].

The room acoustic parameters calculated are reverberation time $T_{20}$ according to ISO 3382-2, speech clarity $C_{50}$ in $\mathrm{dB}$, and sound strength $G$ in $\mathrm{dB}$ according to ISO 3382-1.

Speech clarity is defined as

$$
C_{50}=10 \log \left(\frac{\int_{0}^{0.05} p^{2}(t) d t}{\int_{0}^{\infty} p^{2}(t) d t}\right)
$$

where $p(t)$ is the impulse response at the measurement point.

Sound strength is defined as

$$
G=10 \log \left(\frac{\int_{0}^{\infty} p^{2}(t) d t}{\int_{0}^{\infty} p_{10}^{2}(t) d t}\right)
$$

where $p(t)$ is the impulse response at the measurement point and $p_{10}(t)$ is the impulse response measured at $10 \mathrm{~m}$ in a free field.

An omni-directional sound source is required for measurement of the acoustical parameters.

The model comprises the following steps:

Basic formulas are derived in Section 3.1 comprising

- Establish a general expression for the energy sound decay in a two-system SEA model.

- Express the total sound energy decay in the parameter sound strength $G$ as defined in ISO 3382-1.

- From the expression for the total sound energy decay, derive an expression for the speech clarity $C_{50}$ and the reverberation time $T_{20}$.

Estimation of the inherent parameters in the basic formulas are presented in Section 3.2 comprising

- Subdivide the total sound field into a grazing and non-grazing part where grazing refers to sound waves propagating almost parallel to the absorbent ceiling.

- Calculate the angle-dependent absorption coefficient, Section 3.2.1.

- Estimate the number of modes in the grazing subsystem as well as a representative absorption coefficient, Section 3.2.2.

- Estimate the number of modes in the non-grazing subsystem as well as a representative absorption coefficient, Section 3.2.3. Two approaches for estimation of the number of non-grazing waves were used: one empirical and one theoretical. 
- Based on a 2-dim and 3-dim reverberation formula, estimate the reverberation times $T_{g}$ and $T_{n g}$ corresponding to the grazing and non-grazing subsystem, respectively. See Section 3.2.4.

- By knowing $T_{g}$ and $T_{n g}$ and the number of modes in each subsystem, the energy ratio $C$ for the grazing and non-grazing sound fields in the formula for sound strength $G$ can be calculated.

As an effect of the subdivision of the total sound field into a grazing and non-grazing part, the scattered and absorbed sound, due to objects such as furniture in the room, can be interpreted as a coupling loss factor between the two subsystems, see Figure 1. The coupling loss factor is reformulated as an equivalent scattering absorption area, denoted as $A_{s c}$. A corresponding measurement method of $A_{s c}$ is suggested. See further Section 3.2.5.



Figure 1. The SEA model.

As the distance $r$ is included in the model, the room acoustic parameters as a function of distance can be calculated. However, in the calculations performed, a representative value of $r$ is used. See Equation (41).

The theoretical background for the model is presented in the next chapter and verifying measurements in Section 5. The new model will hereinafter be referred to as "non-diffuse" and the classical diffuse field model (Sabine) as "diffuse".

\section{Theory}

\subsection{The SEA Model}

The sound field in a room with absorbent ceiling treatment is modelled as an SEA system consisting of two subsystems. One subsystem comprises non-grazing waves and the other comprises grazing waves. The term grazing refers to the angle of incidence towards the ceiling absorber. Thus, grazing comprises waves travelling almost parallel to the absorbent ceiling. The coupling loss factor between the two subsystems is related to the energy transfer from the grazing subsystem to the non-grazing subsystem. This energy transfer is most often due to the interior fittings in the room such as furniture, but could also be due to a tilting wall, for example. The back-transfer from the non-grazing to the grazing subsystem is neglected. The SEA model is illustrated in Figure 1.

The power flow into the grazing $(g)$ and non-grazing $(n g)$ subsystem $\left(\Pi_{n g}, \Pi_{g}\right)$, as well as the dissipated power $\left(\Pi_{n g, d}, \Pi_{g, d}\right)$, are shown in Figure 1 . The total energy in the subsystems are denoted as $E_{n g}$ and $E_{g}$, respectively. The power lost by the grazing subsystem to the non-grazing is represented by $\Pi_{g, n g}$. Generally, a weak coupling is assumed, i.e., that the losses related to the coupling between the two system is less than the internal losses in the grazing and non-grazing subsystems [54]. 
In a room with non-uniform distribution of absorption, such as the rectangular room with a highly absorbent ceiling and the other surfaces almost reflecting, the energy decay is estimated by

$$
E(t)=E_{n g}(0) e^{-\omega \eta_{n g} t}+E_{g}(0) e^{-\omega \eta_{g} t}
$$

$E_{n g}(0)$ and $E_{g}(0)$ are the initial energies for the non-grazing and grazing subsystems, respectively. The loss factor in the non-grazing and the grazing subsystems are denoted as $\eta_{n g}$ and $\eta_{g}$, respectively.

Using $\Pi=\omega \eta E$ and, assuming that the coupling loss factor is negligibly small compared to the internal losses in the two subsystems, the energy ratio is given by

$$
E(t)=E_{n g}(0)\left(e^{-\omega \eta_{n g} t}+\frac{E_{g}(0)}{E_{n g}(0)} e^{-\omega \eta_{g} t}\right)=E_{n g}(0)\left(e^{-\omega \eta_{n g} t}+\frac{\eta_{n g} \Pi_{g}}{\eta_{g} \Pi_{n g}} e^{-\omega \eta_{g} t}\right)
$$

The condition in Equation (4) above is valid for a rectangular room with absorbent ceiling, but without furniture. Including furniture will lead to the introduction of a coupling loss factor related to the energy transfer from the grazing to the non-grazing sound field, see Figure 1. Replacing $\eta_{g}$ in Equation (4) by $\eta_{g}+\eta_{g, n g}$ where $\eta_{g, n g}$ is the coupling loss factor, the absorbing and scattering effect of furniture can be accounted for. The coupling loss factor is further discussed in Section 3.2.5.

As shown in [55], the ratio $\Pi_{g} / \Pi_{n g}$ is approximately given by $N_{g} / N_{n g}$, where $N_{g}$ and $N_{n g}$ are the number of modes in the grazing and the non-grazing subsystems, respectively.

In geometrical acoustics, sound waves are often represented as rays with a certain sound intensity. Further, in room acoustical calculations, the reverberation time is a wellestablished parameter and normally the frequency depending on reverberation times are studied in frequency bands, usually octave bands.

By converting Equation (4) into sound intensity, assuming octave band values and using the relation $\Delta \Pi_{g} / \Delta \Pi_{n g} \approx \Delta N_{g} / \Delta N_{n g}$, and further introducing the reverberation time $T$ using the relation $\omega \eta=6 \ln (10) / T$, we get

$$
I(t)=I_{n g}(0)\left(e^{-13.8 t / T_{n g}}+\frac{T_{g} \Delta N_{g}}{T_{n g} \Delta N_{n g}} e^{-13.8 t / T_{g}}\right)
$$

The procedure presented for a linear decay by Barron and Lee [27] is applied for the double sloped decay, as given by Equation (5).

The steady-state condition at $t=0$ gives the power balance

$$
W=\omega \eta \frac{I}{c} V
$$

where $W$ is the input power and $\mathrm{V}$ is the room volume.

Assuming a point source and a distance $r_{0}$ between the source and receiver and further, that the sound field at steady-state is diffusewith a reverberation time $T_{n g}$, the intensity at steady-state is given by [56]

$$
I(0)=I_{0} r_{0}^{2} \frac{T_{n g}}{V} \frac{4 \pi c}{6 \ln (10)}=312 I_{0} r_{0}^{2} \frac{T_{n g}}{V}
$$

where $I_{0}$ is the intensity of the direct sound at the distance $r_{0}$ from the sound source.

The total (energy) decay, as given by Equation (5), adjusted towards the steady-state intensity in Equation (7) will be given by

$$
I(t)=312 I_{0} r_{0}^{2} \frac{T_{n g}}{V(1+C)}\left(e^{-13.8 t / T_{n g}}+C e^{-13.8 t / T_{g}}\right)
$$

where

$$
C=\frac{T_{g} \Delta N_{g}}{T_{n g} \Delta N_{n g}}
$$


Including the direct sound gives

$$
I(t)=I_{d}+I_{r e v}
$$

$I_{r e v}$ is given by Equation (8) and $I_{d}$ is the direct sound at distance $r$ given by

$$
I_{d}=\frac{W}{4 \pi r^{2}}
$$

where $W$ is the input power.

Following Barron et al. [27], the sound strength G is calculated. The sound strength G is defined as

$$
G=L_{p}-L_{p, 10}
$$

where $L_{p}$ is the sound pressure level at the measurement point and $L_{p, 10}$ is the sound pressure level at a distance of $10 \mathrm{~m}$ in a free field given by

$$
L_{p, 10}=10 \log \left(\frac{\rho c}{p_{r e f}^{2}} \frac{W}{4 \pi 10^{2}}\right)
$$

where $p_{\text {ref }}$ is $2 \times 10^{-5} \mathrm{~Pa}$.

Combining Equations (8), (10) and (12) gives

$$
G=10 \log \left(\frac{100}{r^{2}}+31,200 \frac{T_{n g}}{V(1+C)}\left(e^{-\frac{13.8 t}{T_{n g}}}+C e^{-\frac{13.8 t}{T_{g}}}\right)\right)
$$

Setting $t=r / c$ [27] i.e., the time for the sound wave to propagate $r$ metres, gives the final expression. This implies that the decay starts after the direct sound arrived at the receiver position.

$$
G=10 \log \left(\frac{100}{r^{2}}+31,200 \frac{T_{n g}}{V(1+C)}\left(e^{-\frac{0.04 r}{T_{n g}}}+C e^{-\frac{0.04 r}{T_{g}}}\right)\right)
$$

The received sound energy is divided into three components, the direct sound $(d)$, the early reflected sound i.e., a delay $<50 \mathrm{~ms}\left(e_{50}\right)$, and the late reflected sound i.e., a delay $>50 \mathrm{~ms}\left(l_{50}\right)$. Using Equation (8) normalized to $I_{0}=W /\left(4 \pi 10^{2}\right)$ gives

$$
\begin{gathered}
d=100 / r^{2} \\
e_{50}=I_{n}(t)-I_{n}(t+50)=31,200 \frac{T_{n g}}{V(1+C)}\left[e^{-\frac{0.04 r}{T_{n g}}}\left(1-e^{-\frac{0.691}{T_{n g}}}\right)+C e^{-\frac{0.04 r}{T_{g}}}\left(1-e^{-\frac{0.691}{T_{g}}}\right)\right] \\
l_{50}=I_{n}(t+0.05)=31,200 \frac{T_{n g}}{V(1+C)}\left(e^{-\frac{0.04 r+0.691}{T_{n g}}}+C e^{-\frac{0.04 r+0.691}{T_{g}}}\right)
\end{gathered}
$$

The sound strength $G$ is given by

$$
G=10 \log \left(d+e_{50}+l_{50}\right)
$$

The speech clarity $C_{50}$ is given by

$$
C_{50}=10 \log \left(\frac{d+e_{50}}{l_{50}}\right)
$$

$T_{20}$ is calculated using the logarithmic version of Equations (8) and the -5 to $-25 \mathrm{~dB}$ dynamical range according to ISO 3382-2.

To calculate $T_{20}, C_{50}$, and $G$, the inherent parameters $T_{n g}, T_{g}$, and $C$ in Equations (8), (17), and (18) have to be estimated. This is described in the next paragraph. 


\subsection{Estimation of the Inherent Parameters $T_{n g}, T_{g}$ and $C$}

This chapter concerns the approach of estimating the inherent parameters in Equations (8), (17), and (18). Estimation of these parameters is of central importance in the model and some detailed explanations are presented in this paragraph. These estimations involve considerations regarding how to define absorption and the number of modes for the grazing and non-grazing sound fields and how to take into account the effect of soundscattering objects in the room. The method involves defining a grazing and non-grazing region, according to Figure 2 . The grazing sector is defined by the grazing angles $\theta_{g}$. For the non-grazing sector, two approaches were used: a theoretical one and an empirical one. Before we go into the derivation of $\theta_{g}$ and the limits for the non-grazing sector, the calculation of the angle-dependent absorption coefficient will be discussed.

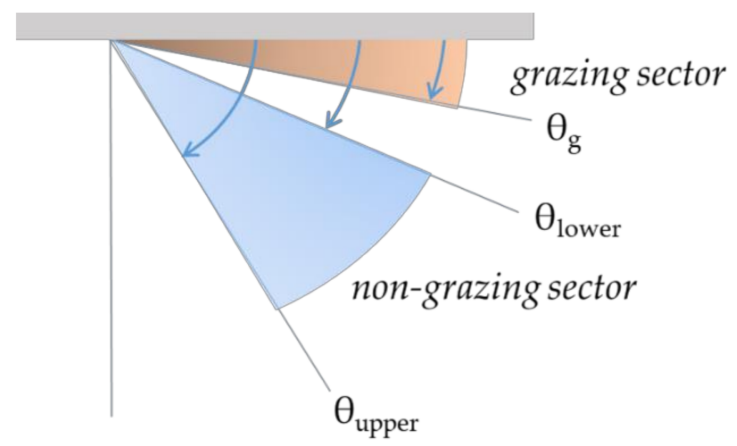

Figure 2. Illustration of the grazing and non-grazing sectors.

\subsubsection{The Angle-Dependent Absorption Coefficient}

For each sector, representative absorption coefficients $\left(\alpha_{n g}, \alpha_{g}\right)$ and a representative number of modes $\left(\Delta N_{n g}, \Delta N_{g}\right)$ have to be determined. It is assumed that the surface impedance of the ceiling absorber is known or can be estimated. Several types of commercial software' are available today for calculating the angle-dependent surface impedances $[57,58]$ for different types of absorbers. In this study, only suspended ceilings of porous material were investigated. For porous absorbers, the surface impedance $Z(f, \theta)$ can be calculated by applying empirical models if the air flow resistivity is known. In this case Miki's model was used [59]. An extended reaction is assumed when calculating $\alpha_{n g}$ and $\alpha_{g}$. The angle-dependent absorption coefficient for a plane sound wave impinging on a plane infinite surface is given by

$$
\alpha(f, \theta)=1-\left|\frac{Z(f, \theta) \cos (\theta)-\rho_{0} c_{0}}{Z(f, \theta) \cos (\theta)+\rho_{0} c_{0}}\right|^{2}
$$

where $Z(f, \theta)$ is the surface impedance at incidence angle $\theta, \rho_{0}$ is the density of air, and $c_{0}$ is the speed of sound. The surface impedance for an extended reaction is calculated as [60]

$$
Z(f, \theta)=\frac{Z_{c} k}{k_{x}}\left[\frac{-j Z_{0} \cot \left(k_{x} d\right)+Z_{c} \frac{k}{k_{x}}}{Z_{0}-j Z_{c} \frac{k}{k_{x}} \cot \left(k_{x} d\right)}\right]
$$

where $k$ is the wave number in the absorber, $k_{x}=\sqrt{k^{2}-k_{0}^{2} \sin ^{2}(\theta)}$ is the normal component of $k, k_{0}$ is the wave number in air, $d$ is the thickness of the absorber, and $Z_{\mathcal{c}}$ is the characteristic impedance of the absorber. The backing impedance $Z_{0}$ is given by

$$
Z_{0}(f, \theta)=-j\left(\rho_{0} c_{0} \frac{k_{0}}{k_{x}}\right) \cot \left(k_{0} d_{0} \cos \theta\right)
$$

where $d_{0}$ is the depth of the air cavity behind the absorber. 
The characteristic impedance for the absorber $Z_{c}$ is calculated by Miki's model according to

$$
Z_{c}=\rho_{0} c_{0}\left[1+0.070\left(\frac{f}{\sigma}\right)^{-0.632}-j 0.107\left(\frac{f}{\sigma}\right)^{-0.632}\right]
$$

and wave number

$$
k=\frac{\omega}{c}\left[1+0.109\left(\frac{f}{\sigma}\right)^{-0.618}-j 0.160\left(\frac{f}{\sigma}\right)^{-0.618}\right]
$$

The only material parameter needed for Miki's formula is the air flow resistivity $\sigma$ of the porous material. Miki's formula is an improvement of the Delany and Bazley model [61]. Another modification of the Delany and Bazley model has been developed by Komatsu [62].

The extended reaction (the angle-dependent impedances) is of particular importance for accurate estimation at low frequencies. This is illustrated in Figure 3 where local and extended reactions are compared for the reverberation time $T_{20}$ measured in a sparsely furnished room with dimensions $7.56 \mathrm{~m} \times 7.30 \mathrm{~m} \times 3.50 \mathrm{~m}$ and with a $15 \mathrm{~mm}$ thick absorbent ceiling at a mounting height of $200 \mathrm{~mm}$ (case 4 in Section 4). The figure shows the results using extended vs. local reaction in the model. Considerable deviation at low frequencies $(125 \mathrm{~Hz}$ and $250 \mathrm{~Hz})$ appears.

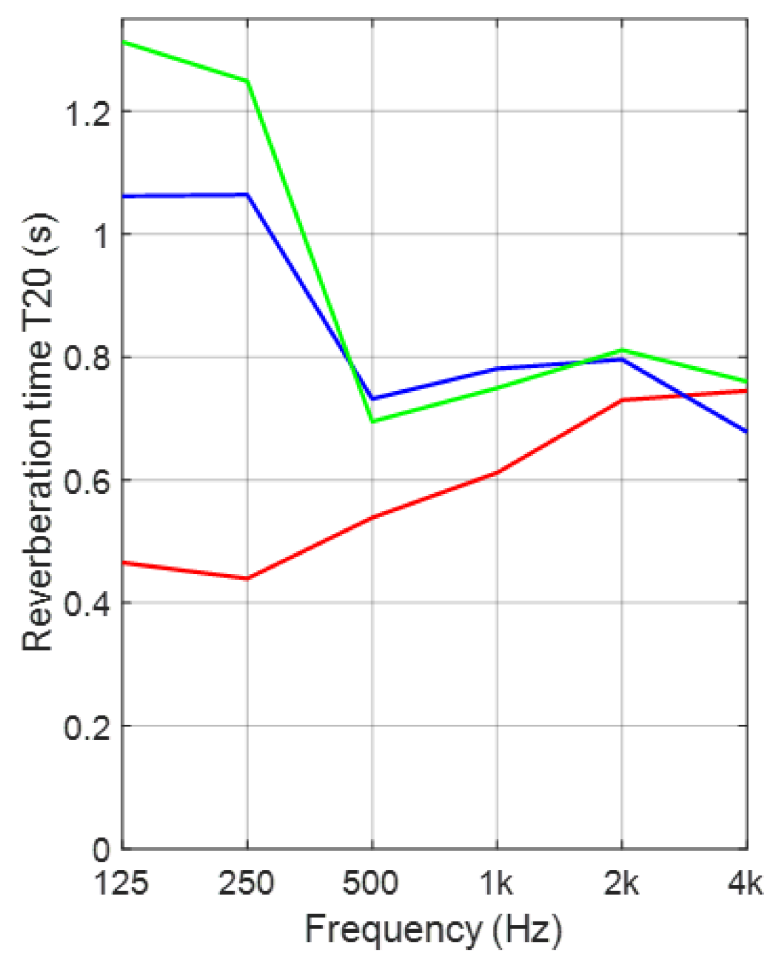

Figure 3. Local vs. extended reaction. Calculations according to the SEA model in a classroom with a $15 \mathrm{~mm}$ thick porous ceiling absorber with a mounting height of $200 \mathrm{~mm}$ (case 4 in the Section 5). Calculated local reaction (red), measured (blue), calculated and extended reaction (green).

\subsubsection{Estimation of $\alpha_{g}$ and $\Delta N_{g}$}

To calculate the total energy decay, Equation (8) in Section 3.1, the number of modes in each sector and the corresponding reverberation times must be known. In this paragraph and the following paragraph, we will firstly estimate the representative absorption coefficients $\alpha_{g}$ and $\alpha_{n g}$ for the grazing and non-grazing sectors in Figure 2, as well as the number of modes $\Delta N_{g}$ and $\Delta N_{n g}$ in each sector. 
The grazing sector is defined by an angle $\theta_{g}$ given by

$$
\theta_{g}=\arccos \left(\frac{c}{4 f L_{x}}\right)
$$

The derivation of $\theta_{g}$ is given in Appendix A. The grazing sector in the wavenumber space is illustrated in Figure 4.

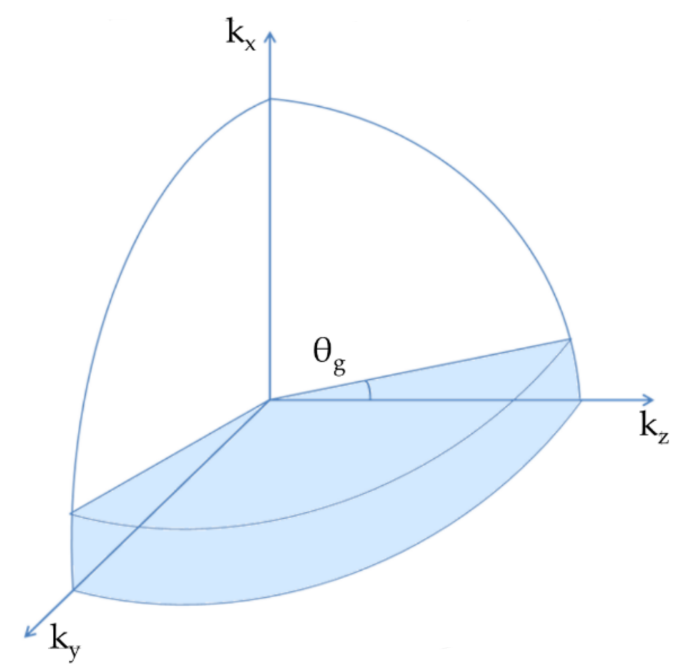

Figure 4. Grazing sector in the wavenumber space.

By knowing the surface impedance of the ceiling, the angle-dependent absorption coefficient can be calculated. The grazing absorption coefficient $\alpha_{g}$ is then calculated as the average absorption coefficient in the grazing region, i.e., between $\pi / 2-\theta_{g}$ and $\pi / 2$. This absorption is often quite small but not negligible when compared to the total absorption for the grazing field. Equation (26) is a high-frequency estimation. At low frequencies, i.e., at $125 \mathrm{~Hz}$ and $250 \mathrm{~Hz}$, the grazing absorption is estimated by

$$
\alpha_{g, \text { ceiling }}=\pi \rho c A_{x l}^{\prime}
$$

where $A_{x l}^{\prime}$ is the real part of the admittance for the ceiling absorber. $A_{x l}^{\prime}$ is given by the real part of $1 / Z$, where $Z$ is given by Equation (22), assuming an extended reaction. The derivation of Equation (27) is given in Appendix B.

The number of grazing modes in the frequency band $\Delta f$ is given by [55]

$$
\Delta N_{g}\left(\theta_{g}\right)=\left[\left(\frac{4 \pi f^{2} V}{c^{3}}\right) \cos \left(\frac{\pi}{2}-\theta_{g}\right)+\left(\frac{2 f}{c^{2}}\right)\left(\pi L_{y} L_{z}+\theta_{g}\left(L_{x} L_{z}+L_{x} L_{y}\right)\right)+\left(\frac{1}{c}\right)\left(L_{y}+L_{z}\right)\right] \Delta f
$$

where $V$ is the volume and $L_{x}, L_{y}$, and $L_{z}$ are height, length, and width of the room, respectively. As $\theta_{g} \rightarrow 0$, the number of grazing modes corresponds to the tangential and axial modes in the $y z$ plan.

\subsubsection{Estimation of $\alpha_{n g}$ and $\Delta N_{n g}$}

To estimate $\alpha_{n g}$, an intermediate step was used. This step includes the introduction of a weighted normalised absorption coefficient given by

$$
\alpha_{n}(f, \theta)=\frac{\alpha(f, \theta) \Delta N(f, \theta)}{\max (\alpha(f, \theta) \Delta N(f, \theta))}
$$

In this expression, $\Delta N(f, \theta)$ is the number of modes as a function of frequency and angle, as given by Equation (28) replacing $\theta_{g}$ with $\theta$. The absorption coefficient $\alpha(f, \theta)$ is the angle-dependent absorption coefficient given by Equation (21), assuming an extended 
reaction. The non-grazing absorption coefficient $\alpha_{n g}$ is given by Equation (21) for an angle $\left(\theta_{n g}\right)$ corresponding to the maximum value in the distribution given by Equation (29).

Examples of this distribution are given for case 1 in Section 4 and for the frequencies $250 \mathrm{~Hz}$ and $4000 \mathrm{~Hz}$, see Figure 5. In the classical diffuse field assumption, the angledependent absorption coefficient is weighted by the factor $\sin (2 \theta)$, according to the Paris formula [63]. For comparison, the diffuse field weighting $\sin (2 \theta)$ is also shown. As can be seen in the figure, there is a bias between the classical approach and the distribution, according to Equation (29). The representative angle for the non-grazing absorption coefficient is somewhat higher compared to the $\sin (2 \theta)$. For the higher frequency, we see that the classical weighting corresponds to almost 45 degrees, as expected. The irregular shape at $250 \mathrm{~Hz}$ is due to the assumption of an extended reaction.
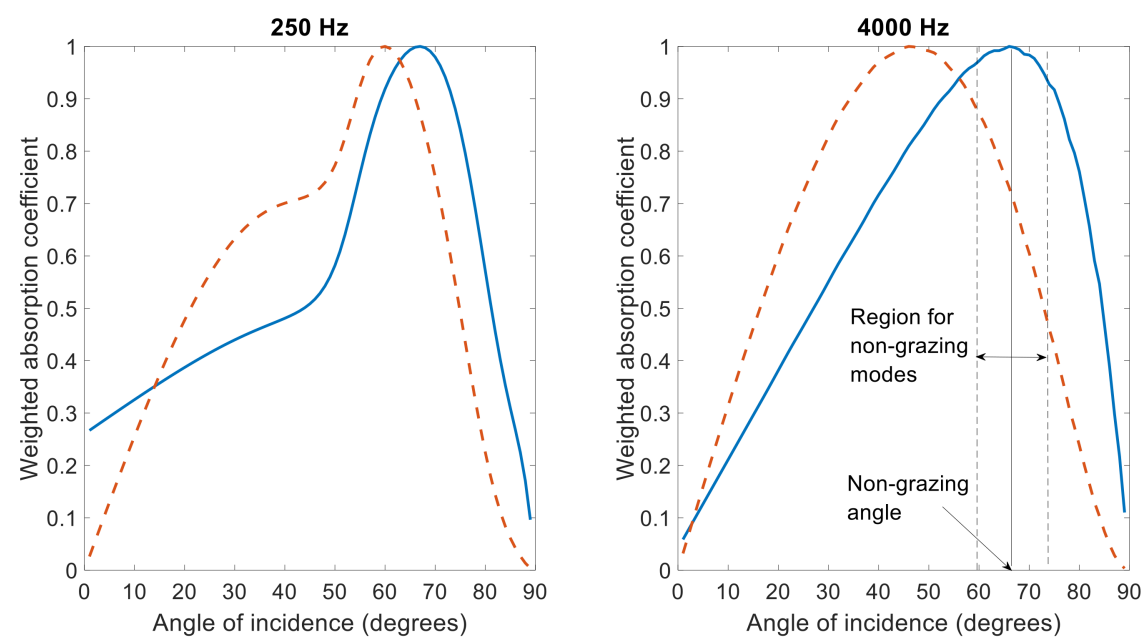

Figure 5. Distribution curves for the normalised weighted absorption coefficient according to Equation (29) for case 1 in Section 4.1. (Red) diffuse model, (blue) non-diffuse model.

Two approaches for determination of $\Delta N_{n g}$ were used: a theoretical one and an empirical one. For the empirical approach, the number of non-grazing modes was determined by adjustment towards experimental results for several configurations where room dimensions and acoustical treatment and furnishing were varied. An approach using minimization of a cost function to perform a curve fitting is presented in [64]. In the empirical method, the upper and lower angles defining the non-grazing sector, see Figure 2, are given by $\theta_{n g \text {, lower }}=\theta_{n g}(1-\Delta \theta)$ and $\theta_{n g \text {, higher }}=\theta_{n g}(1+\Delta \theta)$, where $\Delta \theta$ was estimated by comparison with measurements. Note that the angle of incidence $=\pi / 2-\theta$. Further, $\theta_{\text {higher }}$ is restricted to be less than $\pi / 2$. The values for $\Delta \theta$ is given in Table 1 for the octave bands $125 \mathrm{~Hz}$ to $4000 \mathrm{~Hz}$.

Table 1. Empirical determined limit parameter $\Delta \theta$ for defining the non-grazing region.

\begin{tabular}{ccccccc}
\hline Frequency Hz & 125 & 250 & 500 & 1000 & 2000 & 4000 \\
\hline$\Delta \theta$ & 0.63 & 0.31 & 0.14 & 0.17 & 0.07 & 0.08 \\
\hline
\end{tabular}

The number of modes in the non-grazing sector $\Delta N_{n g}$ in Figure 2 is given by the repeated use of Equation (28) and is given by

$$
\Delta N_{n g}=\Delta N_{g}\left(\theta_{n g, u p p e r}\right)-\Delta N_{g}\left(\theta_{n g, l o w e r}\right)
$$


The theoretical approach involves calculating the number of modes for the non-grazing sector $\Delta N_{n g}$ as

$$
\Delta N_{n g}=\frac{1}{\alpha_{n g}} \int_{0}^{\pi / 2} \alpha(f, \theta) N(f, \theta) d \theta
$$

where $\alpha_{n g}$ is the absorption coefficient corresponding to the angle defined by the maximum in the weighted normalized absorption coefficient given by Equation (29). By knowing this non-grazing angle, see Figure 5 right, the non-grazing absorption coefficient $\alpha_{n g}$ can be given by Equation (21).

For a room with dimensions $7.56 \mathrm{~m} \times 7.30 \mathrm{~m} \times 3.50 \mathrm{~m}$ and with an absorbent ceiling corresponding to case 1 in Table 2, the number of included modes in the non-grazing group given by the empirical and the theoretical approaches are compared in Figure 6. At lower frequencies $(125 \mathrm{~Hz}$ and $250 \mathrm{~Hz})$, the correspondence is good. At higher frequencies, the theoretical estimation gives significantly higher values compared to the empirical one. The consequence of this discrepancy will be further discussed in Section 5.

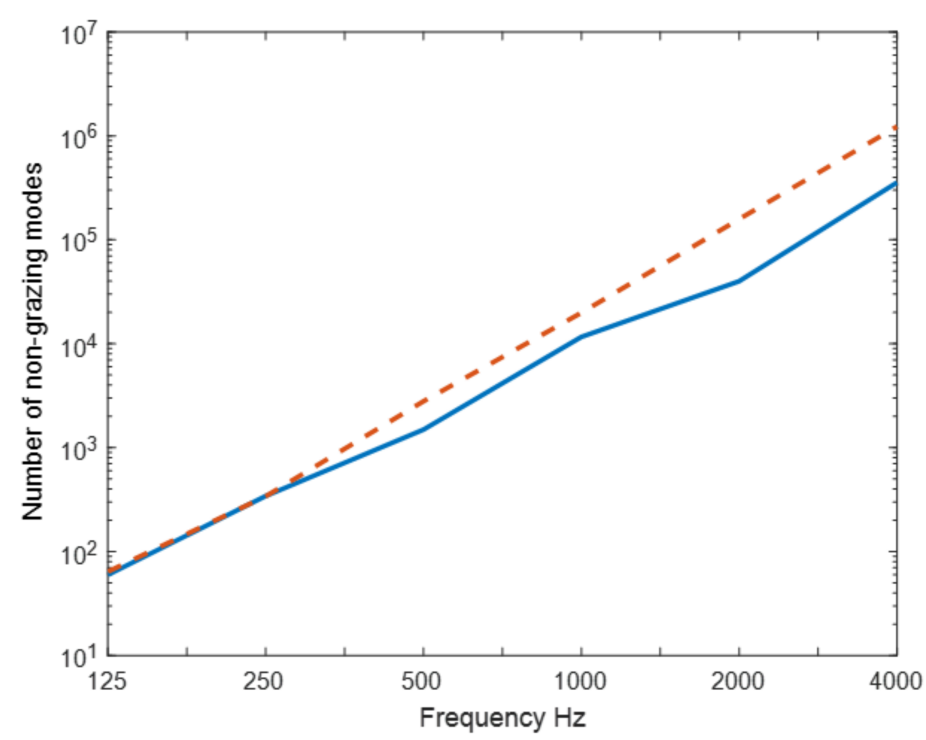

Figure 6. The number of modes in the non-grazing sector estimated by the empirical (solid) and theoretical (dashed) approaches.

The empirical and theoretical approaches described above are used for frequencies of $500 \mathrm{~Hz}$ and above. At $125 \mathrm{~Hz}$ and $250 \mathrm{~Hz}$, the non-grazing absorption coefficient is estimated in the same way as the grazing one at low frequencies, i.e.,

$$
\alpha_{n g, \text { ceiling }}=\pi \rho c A_{x l}^{\prime}
$$

where $A_{x l}^{\prime}$ is the real part of the admittance for the ceiling absorber, see Equation (27).

By knowing the number of modes in each sector, i.e., $\Delta N_{g}$ and $\Delta N_{n g}$, and the representative absorption coefficients $\alpha_{g}$ and $\alpha_{n g}$, we can go on and estimate the corresponding reverberation times $T_{g}$ and $T_{n g}$.

\subsubsection{Estimation of $T_{g}$ and $T_{n g}$}

The non-grazing reverberation time $T_{n g}$ is given by

$$
T_{n g}=\frac{0.161 \mathrm{~V}}{A_{n g, \text { ceiling }}+A_{\text {furniture }}+A_{\text {surface }}+4 m V}
$$

where $A_{n g, \text { ceiling }}=\alpha_{n g} S_{\text {ceiling }}$ and $\alpha_{n g}$ is the absorption coefficient corresponding to the angle given by the maximum in the weighted normalized absorption coefficient, as described 
in Section 3.2.3. $A_{\text {furniture }}$ is the Sabine equivalent absorption area for the furniture. An estimation of $A_{\text {furniture }}$ is given in [49] as $A_{\text {furniture }}=V_{\text {furniture }}^{2 / 3} . A_{\text {surface }}$ is the equivalent absorption area for the walls and floor. Normally, the absorption coefficients for those surfaces are rather small and can be found in tables, e.g., in [49]. The air absorption is taken into account by the term $4 m V$ where $m$ is the energy attenuation constant in air and $V$ is the room volume.

Equation (33) is similar to the Sabine formula, but the skewness in the energy distribution is taken into account by using $\alpha_{n g}$, as described in the paragraph above.

The grazing reverberation time $T_{g}$ is given by a 2-dim version of Sabine formula [55]

$$
T_{g}=\frac{0.127 \mathrm{~V}}{A_{g, \text { ceiling }}+A_{s c}+A_{\text {surface }}+\pi m V}
$$

where $A_{g \text {,ceiling }}=\alpha_{g} S_{\text {ceiling }}$ and $\alpha_{g}$ represents the absorption coefficient for the grazing sector, as derived in Section 3.2.2. In this formula, we also introduce the parameter equivalent scattering absorption area $A_{s c}$. This parameter quantifies the absorption and scattering effects of furniture and other objects in rooms with absorbent ceiling treatment. Thus, it also accounts for the directional scattering effects that can appear in these types of rooms, depending on the objects' orientation relative to the absorbent ceiling. The estimation of $A_{S C}$ will be further discussed in the next paragraph. $A_{\text {surface }}$ is similar, as in Equation (33). It could be stated that a 2-dimensional statistical absorption coefficient should be used instead of a 3-dimensional one, but as the difference is small [55], $A_{\text {surface }}$ is calculated in the same way, as in Equation (33). It is assumed that the contribution of the floor is small and that it can be represented by the statistical absorption coefficient. However, for the air absorption, the distinction between the 2- and 3-dimensional sound fields is accounted for by using $\pi m V$ instead of $4 m V$.

\subsubsection{Estimation of $A_{S C}$}

The sound-scattering effects of furniture and other objects in rooms will greatly influence the room acoustic parameters in rooms where the absorbent material is concentrated to the ceiling. Reverberation time $T_{20}$ and speech clarity $C_{50}$ will be particularly affected. Sound strength $G$ will normally be less affected as it is related to the steady-state conditions and thus will not be sensitive to the distribution of the absorbent material. To quantify the scattering effect, the following procedure was used.

In the terminology of SEA, the transfer of energy from the grazing to the non-grazing sound field is expressed in a coupling loss factor $\eta_{g, n g}$. The power flow $\Pi_{g, n g}$ from the grazing to the non-grazing subsystem is given by

$$
\Pi_{g, n g}=\omega \eta_{g, n g} E_{g}
$$

where $\eta_{g, n g}$ is the coupling loss factor from the grazing to the non-grazing subsystem and $E_{g}$ is the energy in the grazing subsystem.

The coupling loss factor $\eta_{g, n g}$ can be estimated in a rectangular room with a highly absorptive ceiling. It is assumed that the two-system SEA model is valid for the sound field in the room, both with and without scattering objects (furniture) present. This is very often the case in rooms with absorbent ceiling treatment, as it is really difficult to create isotropic conditions in these types of rooms.

The coupling loss factor is then given by

$$
\eta_{g, n g}=\eta_{g, w i t h ~ o b j}-\eta_{g, \text { without } o b j}
$$

where $\eta_{g, \text { with obj }}$ is the grazing loss factor with objects in the room and $\eta_{g}$, without obj is the grazing loss factor without objects in the room. These loss factors are determined from the 
reverberation time $T_{20}$, i.e., the late part of the decay curves in the room with and without objects. The relation between the reverberation time $T$ and the loss factor is given by

$$
\eta=\frac{6 \ln 10}{\omega T}
$$

In a two-dimensional sound field, an equivalent scattering absorption area can be defined as [55]

$$
A_{s c}=\frac{\pi \omega V}{c} \eta_{g, n g}
$$

where $c$ is the speed of sound and $V$ is the room volume.

Combining Equations (36)-(38) gives the equivalent scattering absorption area for objects as

$$
A_{s c}=0.127 V\left(\frac{1}{T_{20, \text { with }}}-\frac{1}{T_{20, \text { without }}}\right)
$$

where $T_{20 \text {, with }}$ and $T_{20, \text { without }}$ are the reverberation times in the room with ceiling absorber, with and without objects, respectively. Equation (39) assumes that the late reverberation time $T_{20}$ in a room with a highly absorptive ceiling is determined by a two-dimensional sound field. The measure $A_{s c}$ is affected by the sound scattered into the ceiling and by the absorption of the objects. This measure is similar to the equivalent absorption area used in Sabine formula. It is used in the same way in Equation (34).

Of course, the $A_{s c}$ will depend on the ceiling absorption properties. However, if the mean absorption coefficient of the ceiling absorber, for the mid and high frequencies, is larger than about 0.7, we will obtain a reasonable estimation of $A_{s c}$ that can be used in most common situations of rooms with absorbent ceilings [65].

The $A_{s c}$ for the investigated furniture configurations were measured according Equation (39) and are further discussed in the Section 5.

\subsection{Summary}

By knowing $T_{g}, T_{n g}, \Delta N_{g}$, and $\Delta N_{n g}$, the coefficient $C$ in the basic formulas in Section 3.1 can be calculated. It is given by

$$
C=\frac{T_{g} \Delta N_{g}}{T_{n g} \Delta N_{n g}}
$$

It is possible to calculate the distance $r$ between the sound source and the receiver for the actual positions, but in our calculations a representative distance was used given by

$$
r=\frac{1}{2} \sqrt{L_{y}^{2}+L_{z}^{2}}
$$

where $L_{y}$ and $L_{z}$ are the width and length of the rectangular room, respectively.

Thus, all parameters are given and can be inserted into Equations (16)-(18) for further calculation of $C_{50}$, and G. $T_{20}$ is calculated using the logarithmic version of Equation (8).

It should also be mentioned that, as the number of grazing and non-grazing modes are mainly related to the floor area and the volume of the room, it is of interest to investigate the model's applicability for other room shapes than rectangular, as long as the ceiling absorber is parallel to the floor.

\section{Measurements and Methods}

\subsection{Measurement Configurations}

The measurements were performed in a mock-up of a classroom with dimension length $\times$ width $\times$ height $=7.56 \mathrm{~m} \times 7.30 \mathrm{~m} \times 3.50 \mathrm{~m}$, where $3.50 \mathrm{~m}$ refers to the height to the soffit. The classroom was sparsely furnished with 10 tables, 19 chairs, and 3 shelves, see Figure 7. 

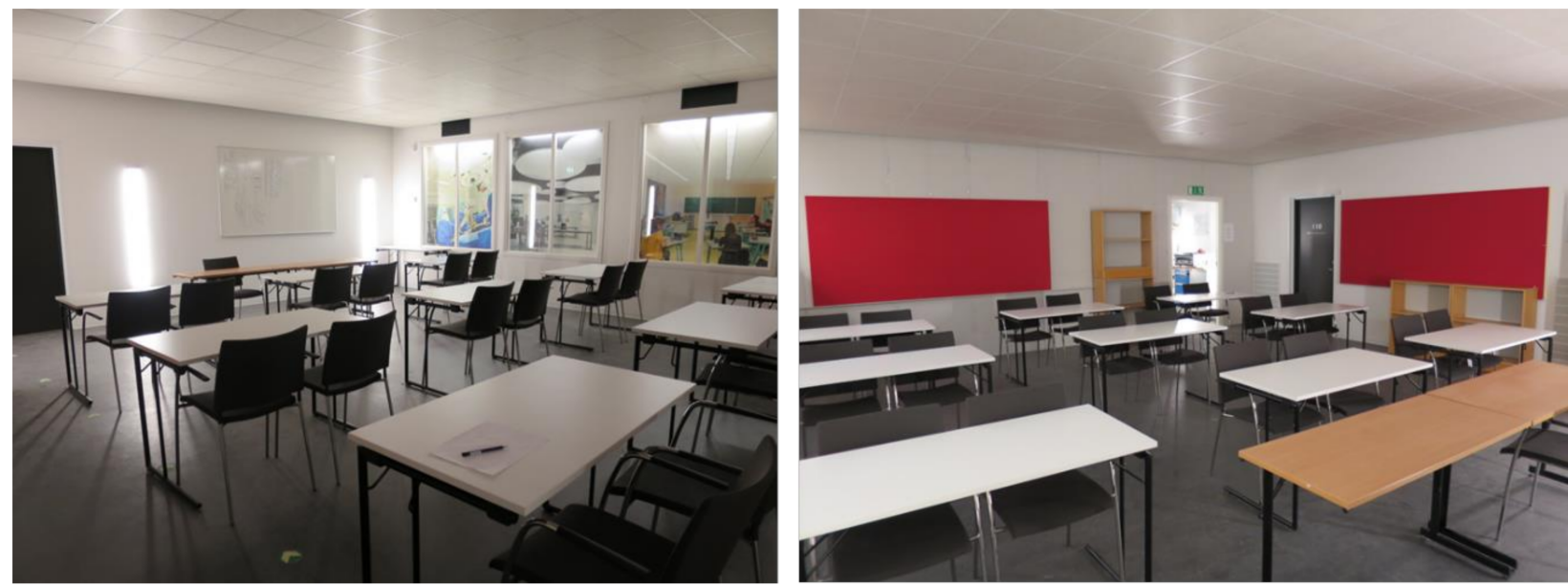

Figure 7. Sparsely furnished classroom mock-up. To the right with wall panels on two adjacent walls.

Two types of suspended ceilings were tested at two mounting heights. One of the suspended ceilings was tested in combination with wall panels on two adjacent walls, see Figure 7 right. The different configurations and specification of the material used are presented in Table 2.

Table 2. Measurement configurations.

\begin{tabular}{|c|c|c|c|}
\hline Case & Ceiling and Wall Panels & $\begin{array}{l}\text { Mounting Height (Depth of Air } \\
\text { Cavity) of Suspended Ceiling (mm) }\end{array}$ & $\begin{array}{c}\text { Air Flow Resistivity of } \\
\text { Ceiling Absorber (kPas/m²) }\end{array}$ \\
\hline 1 & $\begin{array}{l}50 \mathrm{~mm} \text { glasswool ceiling absorber * } \\
\text { no wall panels }\end{array}$ & 750 & 11.8 \\
\hline 2 & $\begin{array}{l}15 \mathrm{~mm} \text { glasswool ceiling absorber **, } \\
\text { no wall panels }\end{array}$ & 785 & 77.8 \\
\hline 3 & $\begin{array}{l}15 \mathrm{~mm} \text { glasswool ceiling absorber } * *, 6.48 \mathrm{~m}^{2} \\
40 \mathrm{~mm} \text { glasswool wall absorber }{ }^{* *} \text { distributed } \\
\text { on two adjacent walls and directly mounted on } \\
\text { the walls, see Figure } 7 .\end{array}$ & 785 & NA \\
\hline 4 & $15 \mathrm{~mm}$ glasswool ceiling absorber ** & 185 & 77.8 \\
\hline 5 & $50 \mathrm{~mm}$ glasswool ceiling absorber * & 150 & 11.8 \\
\hline
\end{tabular}

* Ecophon Industry Modus, ${ }^{* *}$ Ecophon Gedina A, ${ }^{* * *}$ Ecophon Wall Panel A. Note: the air flow resistivity is only used as input data for the ceiling absorbers and not for the wall panels. For the wall panels the practical absorption coefficients are used, see Figure 8.

The absorption data for the products used are presented in Figure 8. The absorption coefficients were measured according to ISO 354 [45] and evaluated by ISO 11654 [66]. This presentation of absorption data as a practical absorption coefficient is common practice by manufactures of absorbent ceilings.

\subsection{Measurement Method}

The room impulse responses were measured using the Dirac system (Dirac type 7841, v.6.0). An exponential sweep signal was fed to an omnidirectional loudspeaker and recorded by an omnidirectional microphone. Two loudspeaker positions at the front of the classroom were used and, for each loudspeaker position, six microphone positions were used throughout the room. No microphone positions were closer than $2 \mathrm{~m}$ to the loudspeaker and none were closer than $1 \mathrm{~m}$ to any of the room surfaces.

The room acoustic parameters measured were reverberation time $T_{20}(\mathrm{~s})$, speech clarity $C_{50}(\mathrm{~dB})$, and sound strength $G(\mathrm{~dB}) . C_{50}$ and $G$ are defined in ISO 3382-1. $T_{20}$ was evaluated according to ISO $3382-2$ using the interval -5 to $-25 \mathrm{~dB}$ of the decay curve. The sound 
strength $G$ was measured using a constant sound power source (Nor278, Norsonic). The sound power source was located in the same positions as the loudspeaker.

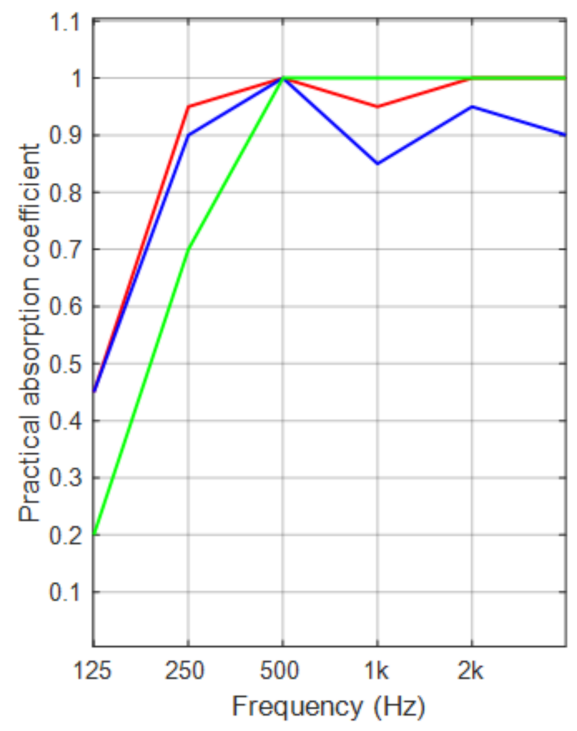

Figure 8. The practical absorption coefficients for the ceiling absorbers and wall panels used in the experiments. (Red) Ecophon Industry Modus 50 mm, (blue) Ecophon Gedina A 15 mm, (green) Wall Panel A $40 \mathrm{~mm}$.

\subsection{Repeatability}

A repeatability test was performed for the measurement procedure described above. The measurements were repeated five times. Between each measurement, the loudspeaker and the microphone were taken out of the room and reinstalled at different positions. For details see [67].

In Table 3, the uncertainty is given for the measurement procedure.

Table 3. Uncertainty interval related to repeatability, corresponding to a $95 \%$ confidence interval, for the measurement procedure used in the experiments.

\begin{tabular}{cccc}
\hline & $G_{\text {avg }}(\mathbf{d B})$ & $C_{50, a v g}(\mathbf{d B})$ & $\boldsymbol{T}_{20, a v g}(\mathbf{s})$ \\
\hline $125 \mathrm{~Hz}$ & \pm 0.61 & \pm 0.56 & \pm 0.077 \\
$250 \mathrm{~Hz}$ & \pm 0.30 & \pm 0.29 & \pm 0.018 \\
$500 \mathrm{~Hz}$ & \pm 0.40 & \pm 0.29 & \pm 0.010 \\
$1000 \mathrm{~Hz}$ & \pm 0.25 & \pm 0.27 & \pm 0.006 \\
$2000 \mathrm{~Hz}$ & \pm 0.37 & \pm 0.38 & \pm 0.010 \\
$4000 \mathrm{~Hz}$ & \pm 0.36 & \pm 0.36 & \pm 0.008 \\
\hline
\end{tabular}

The variations in repeated measurements are less noticeable (JND), according to ISO 3382-1 [1]. This supports the discussion of significant differences in the measurements.

\subsection{Estimation of the Equivalent Scattering Absorption Area $A_{s c}$}

The $A_{s c}$ for the furniture configurations is estimated by Equation (39). The $A_{s c}$ for the furniture in combination with the two ceiling treatments and for the two mounting heights, given in Table 2, were measured. No wall panels were present during these measurements. The results are presented in Section 5.1. The same number of microphone and loudspeaker positions were used, as for the measurements of the room acoustic parameters.

\subsection{Comparison between Measurements and Calculations}

The measurements and calculations were compared for the octave band frequencies $125 \mathrm{~Hz}$ to $4000 \mathrm{~Hz}$. Calculations of $C_{50}$ and $G$ were performed with the formulas presented 
in Section 3, according to Equations (19) and (20). $T_{20}$ was calculated by the logarithmic version of Equation (8) using the -5 to $-25 \mathrm{~dB}$ dynamical range according to ISO 3382-2.

For comparison, calculations according to the Sabine formula were included. The reverberation time $T$ was calculated as

$$
T=\frac{0.161 V}{A_{\text {ceiling }}+A_{\text {furniture }}+A_{\text {surface }}+4 m V}
$$

where $A_{\text {ceiling }}=\alpha_{p} S_{\text {ceiling }}$ and $\alpha_{\mathrm{p}}$ is the practical absorption coefficient given in Figure 8 . $A_{\text {furniture }}=V_{\text {furniture }}^{2 / 3}$ according to the EN 12354-6. For a sparsely furnished room, $V_{\text {furniture }}$ is approximately $1-2 \%$ of the room volume [29]. $A_{\text {surface }}$ and the air absorption were calculated in the same way as in Equation (33).

The absorption coefficients for the floor and walls were estimated from the reverberation time measurements in the empty room, i.e., without an absorbent ceiling. Those values were used both in the diffuse and non-diffuse calculations for calculating $A_{\text {surface }}$.

Assuming a linear decay under diffuse field conditions and a reverberation time, given by Equation (42), $C_{50}$ and $G$ are calculated as

$$
C_{50}=10 \log \left(10^{(6 / T) 0.05}-1\right)
$$

And

$$
G=10 \log \left(\frac{4}{A}\right)+31
$$

where $A=0.16 \frac{V}{T}$ is the equivalent absorption area in $\mathrm{m}^{2}$ sabin and $V$ is the room volume.

\section{Results}

\subsection{Estimation of $A_{s c}$}

The equivalent scattering absorption area $A_{s c}$ for the furniture was measured for configurations 1, 2, 4, and 5 given in Table 2. The $A_{s c}$ is estimated according to Equation (39). In Figure 9, the results are presented together with the averaged values.

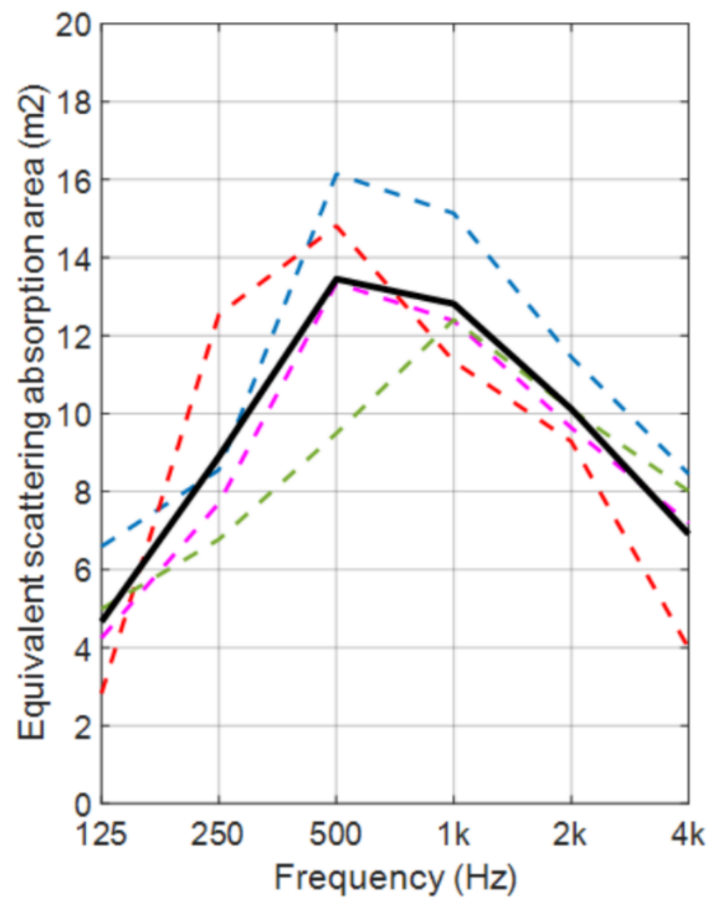

Figure 9. $A_{s c}$ for the furniture estimated from cases 1, 2, 4 and 5 in Table 2, (black) average, (blue) case 4 , (red) case 5, (purple) case 1 and (green) case 2. 
$A_{s c}$ depends on the absorption of furniture as well as the scattered sound energy transmitted to the non-grazing sound field and mainly absorbed by the ceiling absorber. As can be seen in Figure 9, the frequency behavior is quite similar for the different cases despite the fact that there is a variation of the ceiling absorber concerning airflow resistivity, thickness, and mounting height. This supports the idea that, for ceiling absorbers with a reasonably high absorption, see comment in Section 3.2.5, the correction for furniture absorption and scattering by $A_{s c}$ is justified. For furnishing with tables, chairs, and shelves, the highest values of $A_{s c}$ appears for the mid frequencies, as apparent from Figure 9. In practice, it is also possible to define $A_{s c}$ per $\mathrm{m}^{2}$ floor area to obtain a value that can be used for different sizes of rooms. In [29], values of $A_{s c}$ per $\mathrm{m} 2$ floor area are suggested for what can be considered as sparse, normal, and dense furnishing. It is noteworthy that, in EN 12354-6, the correction for furniture and other objects in the room is independent of frequency.

\subsection{Measurement Results}

The measurements results are presented in Figures 10-14, corresponding to the cases 1 to 5 in Table 2. In the figures (a) is the reverberation time $\boldsymbol{T}_{20}$ in seconds, (b) is the speech clarity $C_{50}$ in $\mathrm{dB}$ and (c) is the sound strength $G$ in dB. Comparisons are made between measurements, Sabine calculation and the non-diffuse calculation. For the non-diffuse calculation, both the empirical and the theoretical approaches, discussed in Section 3.2.3, are shown.

a

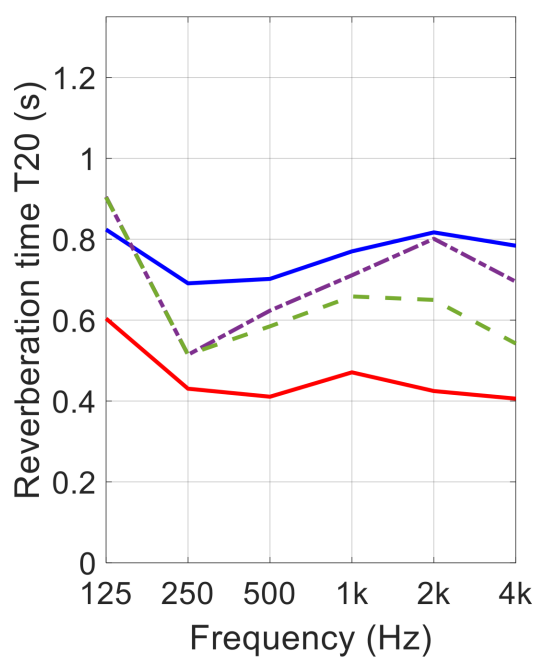

b

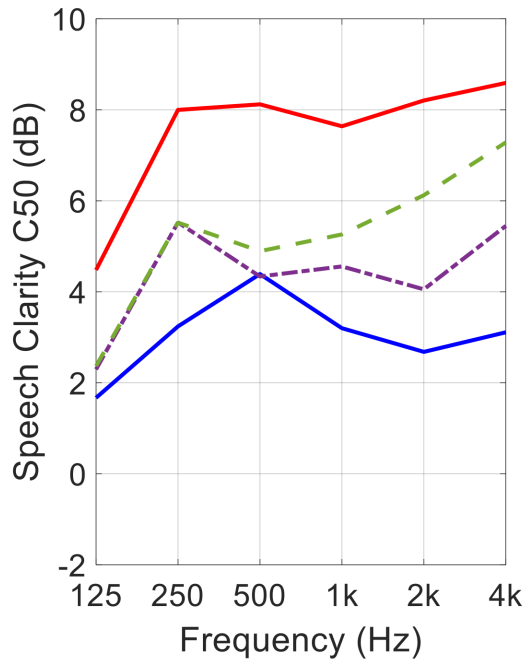

C

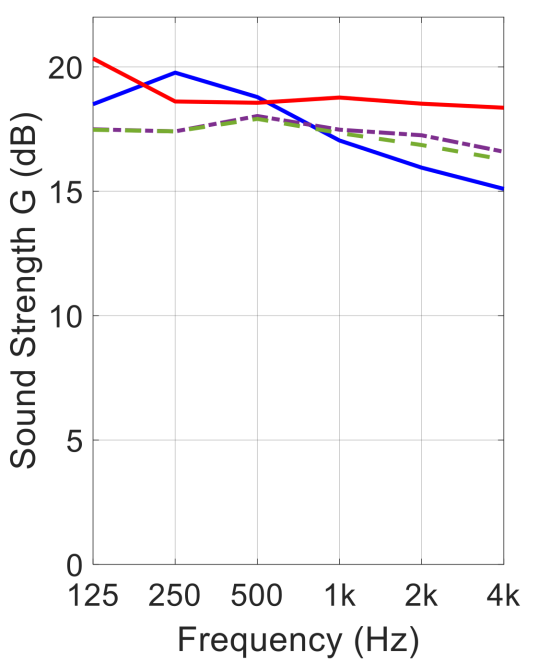

Figure 10. Sparsely furnished room with dimensions $7.35 \times 7.50 \times 3.50 \mathrm{~m}$. Ceiling treatment: $50-\mathrm{mm}$ glass wool absorber at a mounting height (air cavity behind the absorber) of $750 \mathrm{~mm}$. (a) Reverberation time $\boldsymbol{T}_{20}$ in seconds, (b) speech clarity $\boldsymbol{C}_{50}$ in $\mathrm{dB},(\mathbf{c})$ sound strength $G$ in $\mathrm{dB}$. Curves shown are (red) diffuse calculation (Sabine), (blue) measurement, (dashed) nondiffuse calculation, where the number of non-grazing modes is estimated by Equation (31), and (dash-dotted) non-diffuse calculation, where the number of non-grazing modes is empirically estimated, see Table 1 . 
a

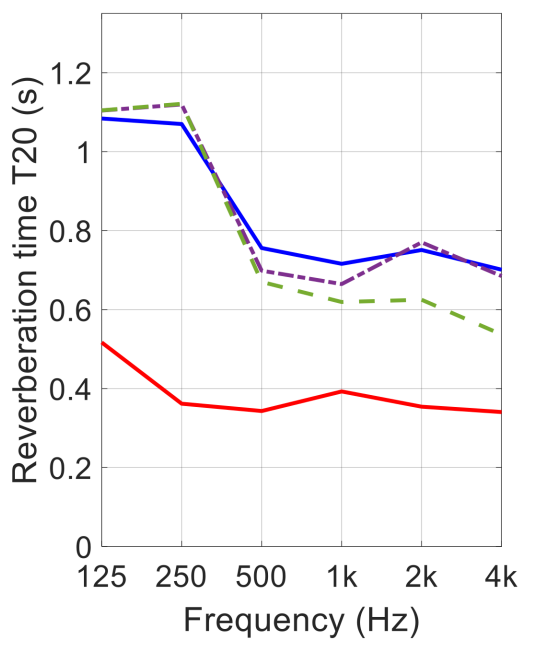

b

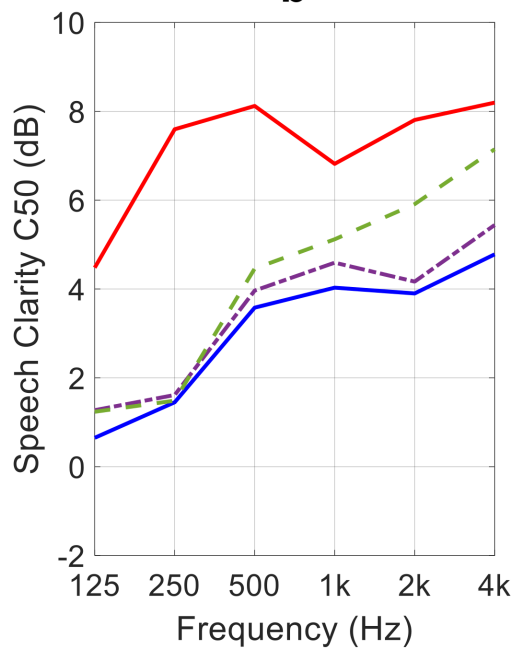

C

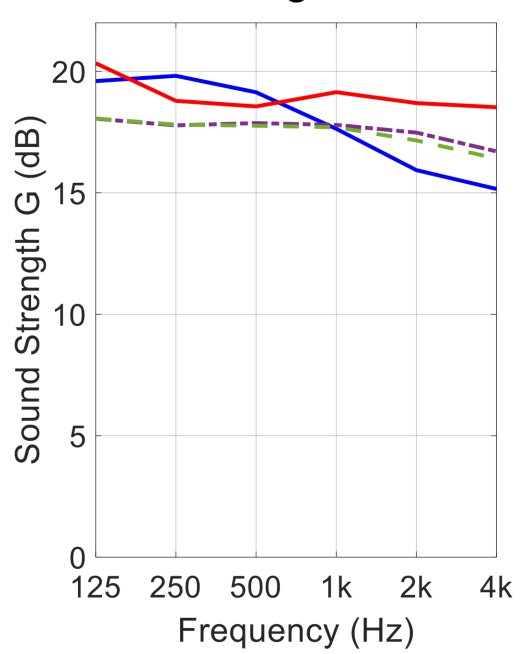

Figure 11. Sparsely furnished room with dimensions $7.35 \times 7.50 \times 3.50 \mathrm{~m}$. Ceiling treatment: $15-\mathrm{mm}$ glass wool absorber at a mounting height (air cavity behind the absorber) of $785 \mathrm{~mm}$. (a) Reverberation time $\boldsymbol{T}_{20}$ in seconds, (b) speech clarity $\boldsymbol{C}_{50}$ in $\mathrm{dB}$, (c) sound strength $G$ in $\mathrm{dB}$. Curves shown are (red) diffuse calculation (Sabine), (blue) measurement, (dashed) nondiffuse calculation, where the number of non-grazing modes is estimated by Equation (31), and (dash-dotted) non-diffuse calculation, where the number of non-grazing modes is empirically estimated, see Table 1 .

a

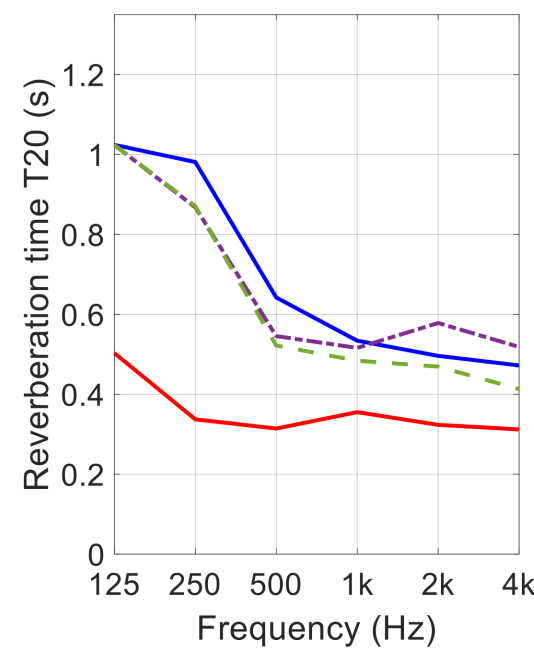

b

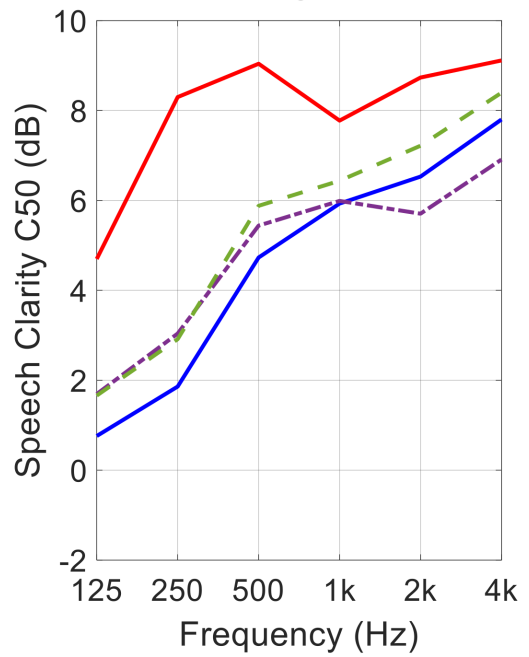

C

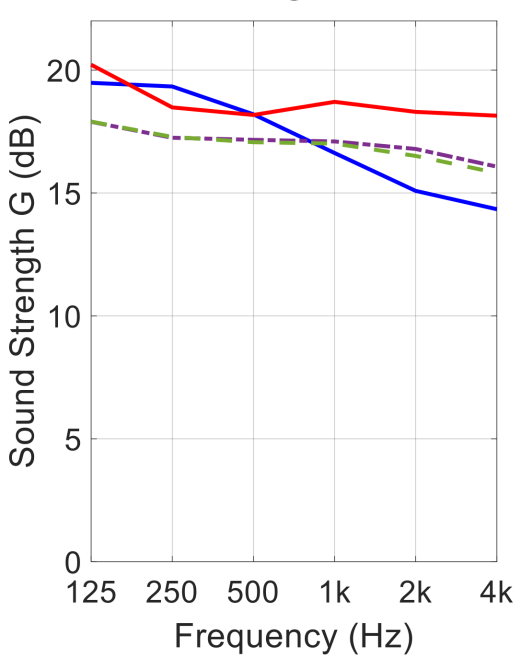

Figure 12. Sparsely furnished room with dimensions $7.35 \times 7.50 \times 3.50 \mathrm{~m}$. Ceiling treatment: $15 \mathrm{~mm}$ glass wool absorber at a mounting height (air cavity behind the absorber) of $785 \mathrm{~mm} .6 .48 \mathrm{~m}^{2} 40 \mathrm{~mm}$ glass wool wall absorber equally distributed on two adjacent walls and directly mounted on the walls, see Figure 7. (a) Reverberation time $T_{20}$ in seconds, (b) speech clarity $C_{50}$ in $\mathrm{dB},(\mathrm{c})$ sound strength $G$ in $\mathrm{dB}$. Curves shown are (red) diffuse calculation (Sabine), (blue) measurement, (dashed) non-diffuse calculation, where the number of non-grazing modes is estimated by Equation (31), (dash-dotted) non-diffuse calculation, where the number of non-grazing modes is empirically estimated, see Table 1. 
a

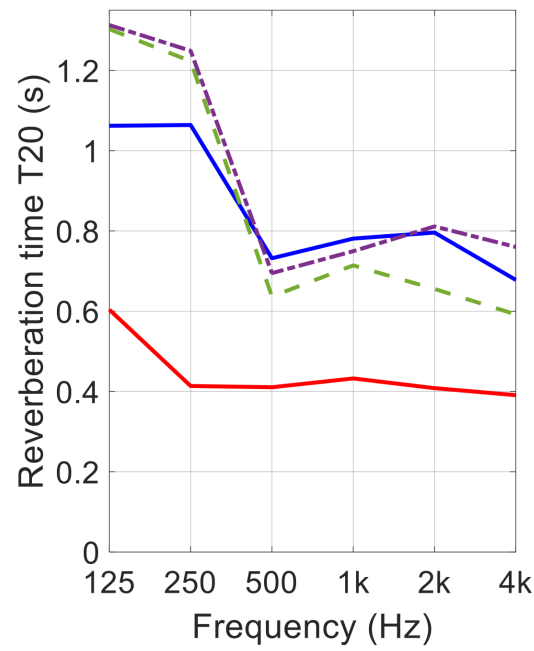

b



C

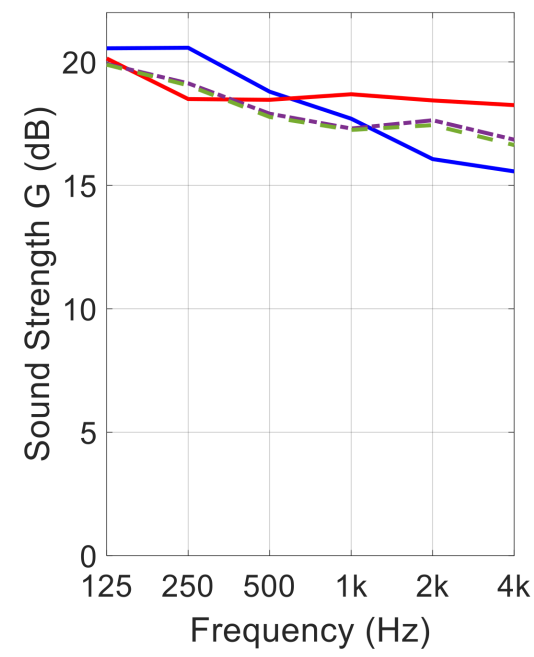

Figure 13. Sparsely furnished room with dimensions $7.35 \times 7.50 \times 3.50 \mathrm{~m}$. Ceiling treatment: $15 \mathrm{~mm}$ glass wool absorber at a mounting height (air cavity behind the absorber) of $185 \mathrm{~mm}$. (a) Reverberation time $\boldsymbol{T}_{20}$ in seconds, (b) speech clarity $C_{50}$ in $\mathrm{dB}$, (c) sound strength $G$ in $\mathrm{dB}$. Curves shown are (red) diffuse calculation (Sabine), (blue) measurement, (dashed) nondiffuse calculation, where the number of non-grazing modes is estimated by Equation (31), (dash-dotted) and non-diffuse calculation, where the number of non-grazing modes is empirically estimated, see Table 1.

a

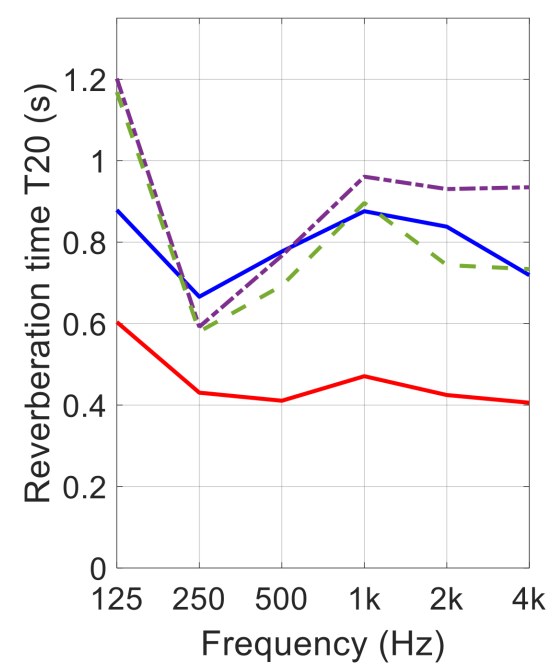

b

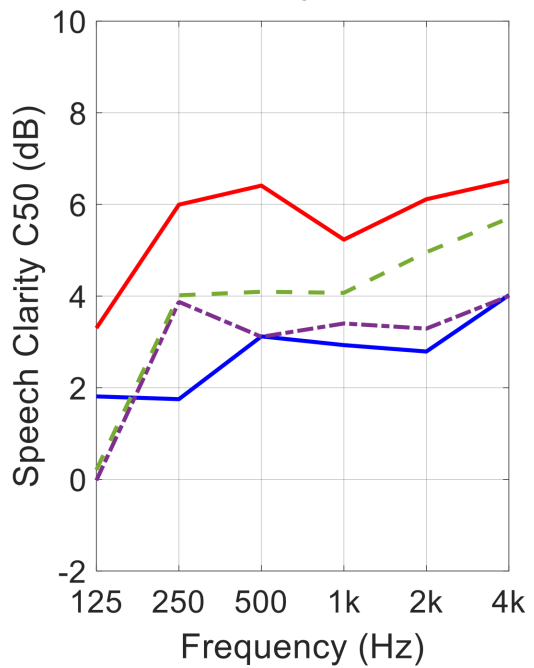

C

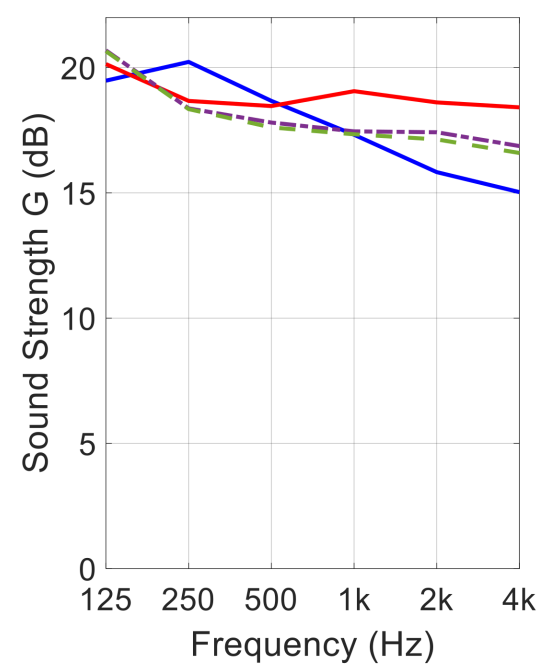

Figure 14. Sparsely furnished room with dimensions $7.35 \times 7.50 \times 3.50 \mathrm{~m}$. Ceiling treatment: $50 \mathrm{~mm}$ glass wool absorber at a mounting height (air cavity behind the absorber) of $150 \mathrm{~mm}$. (a) Reverberation time $\boldsymbol{T}_{20}$ in seconds, (b) speech clarity $\boldsymbol{C}_{50}$ in $\mathrm{dB},(\mathrm{c})$ sound strength $G$ in $\mathrm{dB}$. Curves shown are (red) diffuse calculation (Sabine), (blue) measurement, (dashed) nondiffuse calculation, where the number of non-grazing modes is estimated by Equation (31), and (dash-dotted) non-diffuse calculation, where the number of non-grazing modes is empirically estimated, see Table 1.

Overall, the non-diffuse model fits better with the measurement results than the diffuse model. In particular, the overestimation of the absorption in the diffuse model is reduced in the non-diffuse model. The large differences between the diffuse calculations and the measurement results are typical for sparsely furnished rooms with an absorbent ceiling treatment. The cause of this is the lack of diffusion and the influence of the grazing sound field. Naturally, the empirical estimation given in Table 1 agrees better with measurements than the theoretical approach, according to Equation (31). This is more apparent at the higher frequencies. It is noticeable that the non-diffuse model captures the frequency behavior better than the diffuse one. 
An important feature of the non-diffuse model is the reaction to wall panels. The effect of wall panels is the reduction in the energy in the grazing sound field. In sparsely furnished rooms, this largely influences the late reverberation time and the speech clarity. This is clearly shown in Figure 15. The correspondence between the non-diffuse calculation and measurement is good. For the diffuse model, a much smaller effect is noticed. The effect of wall panels on sound strength $G$ is small. As $G$ is a steady-state measurement, it is mainly related to the total absorption in the room, assuming that the sound field is fairly diffuse before the onset of the decay. During the decay, the degeneration of the sound field towards a grazing sound field will affect reverberation times and speech clarity to a great extent, as shown in the experimental results.

a

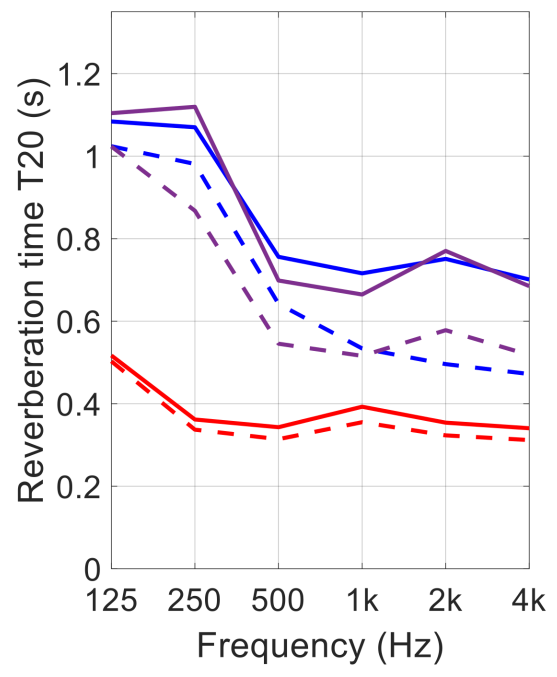

b

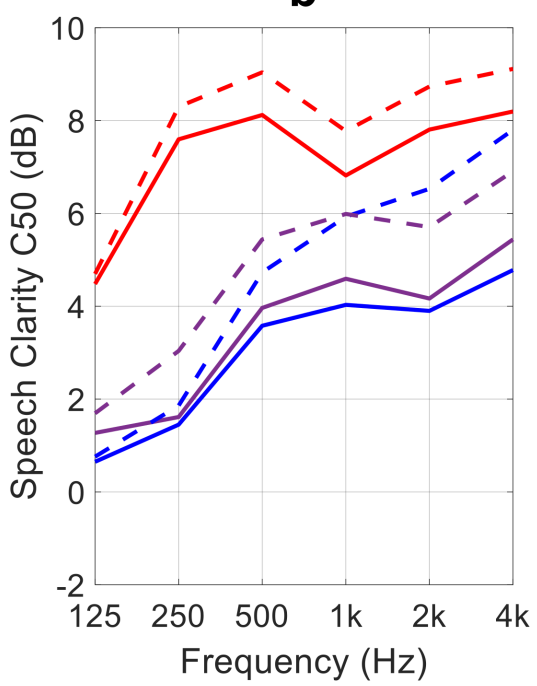

C

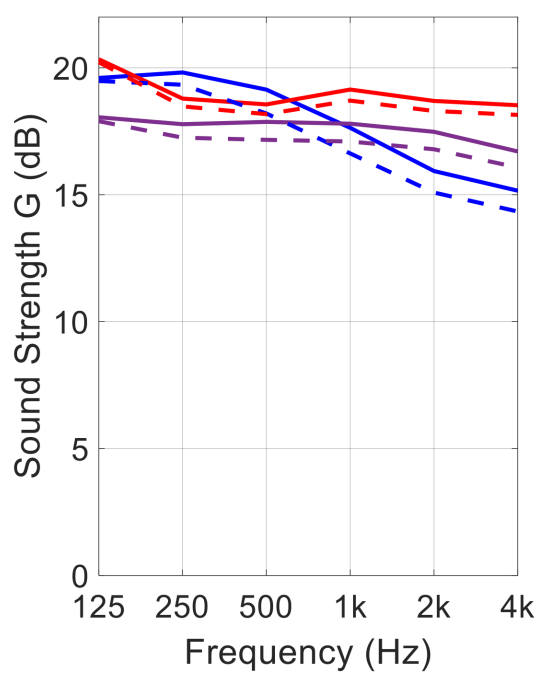

Figure 15. Comparison of case 2 and 3 in Table 2, i.e., the cases with and without wall panels. (a) Reverberation time $T_{20}$ in seconds, (b) speech clarity $C_{50}$ in dB, (c) sound strength $G$ in dB. (Blue solid) measured without wall panels, (blue dashed) measured with wall panels, (purple solid) non-diffuse calculation without wall panels, (purple dashed) non-diffuse calculations with wall panels, (red solid) diffuse calculations without wall panels, and (red dashed) diffuse calculations with wall panels. The empirical approach is used for the non-diffuse calculations, see Section 3.2.3.

Note that the results presented above refer to a sparsely furnished room which is very sensitive to the accuracy of the input data. It is notable that the case with the wall panels decrease the discrepancy between the theoretical and empirical model and also fits better with measurements.

In Figure 16, a comparison of the two ceilings absorbers corresponding to case 1 and 2 in Table 2 is shown. The practical absorption coefficients for these absorbers, as given by the manufactures, is shown in Figure 8. Besides the large difference between the diffuse calculations on the one hand (red curves) and the measurements and nondiffuse calculations on the other (blue and green curves) some other remarks can be made. The practical absorption coefficients, based on ISO 354 measurements, show similar values at $125 \mathrm{~Hz}$ for the two absorbers. Accordingly, the diffuse calculations show the same reverberation time at this frequency. However, the non-diffuse calculations give a large difference at $125 \mathrm{~Hz}$ which also corresponds to the measurements. It is also noteworthy that, at high frequencies, the non-diffuse calculations and the measurements show contradictory behavior in comparison with the diffuse calculations. The diffuse calculations follow the difference in the practical absorption coefficients which is not the case for the measurements and the non-diffuse calculations. This emphasizes the fact that the absorption coefficients measured under reverberant conditions, as in ISO 354, do not comprise sufficient information for the acoustic design of rooms with ceiling treatment. Other information is needed and, in the model presented, the surface impedance of the ceiling absorber is necessary input data. 


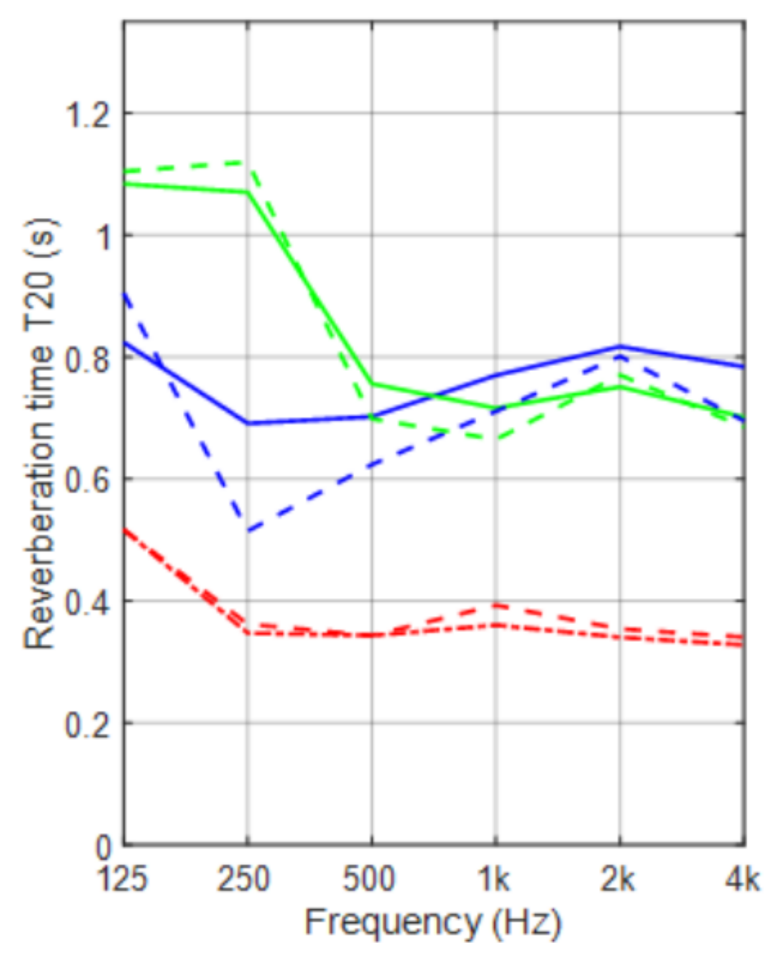

Figure 16. Measured and calculated reverberation times for case 1 and 2 in Table 2. Fifty mm and fifteen $\mathrm{mm}$ thick porous ceiling absorbers at a mounting height of $760 \mathrm{~mm}$ and $785 \mathrm{~mm}$, respectively, were investigated. (Dashed green) $15 \mathrm{~mm}$ absorber, non-diffuse calculation; (solid green) $15 \mathrm{~mm}$ absorber, measurement; (dashed blue) $50 \mathrm{~mm}$ absorber, non-diffuse calculation; (solid blue) $50 \mathrm{~mm}$ absorber, measurement; (dashed red) $50 \mathrm{~mm}$ absorber, diffuse calculation; and (dash-dot red) $15 \mathrm{~mm}$ absorber, diffuse calculation.

\section{Discussion}

A model is presented based on a subdivision of the sound field into a grazing and nongrazing subsystem, where grazing refers to sound waves propagating almost parallel to the absorbent ceiling. An advantage of this approach is its interpretation of sound scattering due to interior equipment such as furniture, diffusors, or similar. The scattering effect is quantified in a parameter related to the energy transfer from the grazing to the non-grazing group. The parameter is denoted as the equivalent scattering absorption area $A_{s c}$ and comprises the scattering and absorbent effect of interior objects in a room with a highly absorptive ceiling. Due to the presumption of an absorbent ceiling, the directional scattering effects of objects will appear. It is assumed that the ceiling absorption is much larger than the average absorption for walls and floors. An average absorption coefficient for the ceiling absorber greater than 0.7 for the octave bands ranging from 250 to $4000 \mathrm{~Hz}$ seems to be sufficient for most practical situations, but this has to be further investigated [65]. There is an assumption concerning sufficiently great ceiling absorption to ensure that the energy reflected back to the non-grazing field can be neglected. It might also be of future interest to specify the conditions for a laboratory configuration as to how to estimate $A_{s c}$. The methodology could be used to give input data for typical furnishing scenarios in different segments such as schools, offices, and healthcare premises. The directional effects of diffusors were studied in a classroom configuration by Arvidsson et al. [67].

In the presented model, it is assumed that the surface impedance is known or can be calculated for the suspended ceiling. Other surfaces are dealt with in a normal way using the practical or statistical absorption coefficients. Data for this can be found in handbooks in acoustics or manufactures' websites. The surface impedance is not a parameter normally provided by the manufacturers of absorbent ceilings. However, several examples of commercial software exist today that calculates the surface impedances for different types of absorbers. 
The need to include more complex boundary conditions for improved accuracy has also been noted in the development of simulation models [68]. Furthermore, the assumption of local reaction was investigated and the benefits of an extended reaction were shown to improve in accuracy, especially at lower frequencies [69].

In the model, the distance from the sound source to the receiver is a parameter. In this investigation, a representative value, see Equation (41), was used. For open-plan offices, it is of interest to calculate the sound propagation over distances corresponding, e.g., to different workplaces. As the model accounts for the distance and takes into account the angle-dependent absorption of the ceiling absorber, it would also be of interest to investigate this application.

Another application where the non-diffuse sound fields appear are sport halls. A common treatment in such rooms is an absorbent ceiling. The present model clarifies the considerable deviation between diffuse field calculations and measurements that often appear in these rooms. It also shows the importance of a more uniform distribution of absorbent material.

The general assumption of the SEA approach and the method for a subdivision into a grazing and non-grazing sound field can be further improved. It is assumed that the ceiling is the most absorptive area in the type of rooms investigated. However, a more precise description of the non-uniform absorption conditions would be valuable. Comparison with field measurements of different room types would clarify the models applicability and point out opportunities for improvements. Similarly, the limits in the method of estimating the equivalent scattering absorption area must be further investigated. The statistical approach requires a certain minimum room volume for the application of the model. This needs further investigation, but experiences so far indicate a room volume larger than $50 \mathrm{~m}^{3}$.

In any event, the purpose of the model is to give a direct and reasonably accurate estimation of room acoustic parameters in rooms with absorbent ceiling treatments. The model accounts for the actual mounting height of the ceiling absorber, including both the scattering and absorbing effects of furniture, and reveals the typical characteristic behavior of sound fields in rooms with ceiling treatment, such as the effects of adding wall absorbers.

\section{Conclusions}

A statistical energy analysis (SEA) model was developed for rooms with absorbent ceiling treatments. The model is based on a subdivision of the sound field into a grazing and non-grazing subsystem where grazing refers to sound waves propagating almost parallel to the absorbent ceiling. The scattering and absorbing effects of furniture and other interior objects is quantified in a measure denoted as the equivalent scattering absorption area $A_{s c}$. This parameter is related to the energy transfer between the grazing and nongrazing subsystem. The back-transfer from the non-grazing to the grazing subsystem is assumed to be negligible. As a consequence, it is assumed that the ceiling absorption is much greater than the average absorption for walls and floors. An average absorption coefficient for the ceiling absorber greater than 0.7 for the octave bands ranging from 250 to $4000 \mathrm{~Hz}$ seems to be sufficient for most practical situations, but this has to be further investigated. In the model, it is assumed that the surface impedance for the suspended ceiling is known or can be calculated. Other surfaces are dealt with in the usual way, using the practical or statistical absorption coefficients. Based on the airflow resistance of the ceiling absorbers investigated, the surface impedances are estimated by the Miki's model, assuming an extended reaction. Thus, the actual mounting height of the ceiling absorber can be accounted for.

The new model was compared with the classical diffuse field model. Experiments were carried out in a classroom mock-up. Two different ceiling absorbers for two different mounting heights were each investigated. One of these cases was also tested in combination with wall panels on two adjacent walls. For all the experiments carried out, the new model shows better agreement with measurements than the classical diffuse field model. The new model reproduces the frequency behaviour of the room acoustic parameters as well 
as accounting for wall panels in closer agreement with measurements than the diffuse field model.

Further comparison with well-documented field measurements is necessary for the fine-tuning of the model, as well as investigation of the methodology used for estimating the equivalent scattering absorption area.

Author Contributions: Writing—original draft preparation, E.N.; writing—review and editing, E.N.; Experiments and investigations related to Sections 3.2.5 and 5.1, E.N. and E.A. All authors have read and agreed to the published version of the manuscript.

Funding: This research received no external funding.

Institutional Review Board Statement: Not applicable.

Informed Consent Statement: Not applicable.

Data Availability Statement: The data presented in this study are available on request from the corresponding author.

Acknowledgments: The authors want to thank Ecophon R\&D and Innovation for providing material, laboratory facilities and equipment. Thanks!

Conflicts of Interest: The authors declare no conflict of interest.

\section{Appendix A}

Derivation of the grazing angle at high frequencies.

A more profound argumentation for the theory outlined in this appendix is given in $[55,70]$.

We consider the rectangular room in Figure A1.

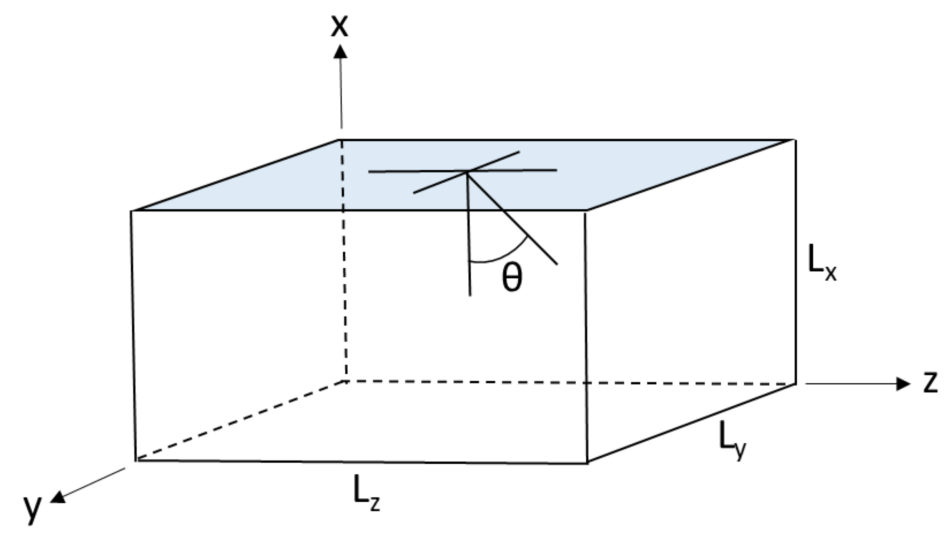

Figure A1. Room with absorbent ceiling.

From the wave equation, the complex wave number is given by

$$
\underline{k}^{2}=\underline{k}_{x}^{2}+\underline{k}_{y}^{2}+\underline{k}_{z}^{2}
$$

and

$$
\cos (\theta)=\frac{k_{x}}{k}
$$

where $k_{x}$ and $k$ is the real part of $\underline{k}_{x}$ and $\underline{k}$, respectively.

Near the absorbing ceiling we expect a phase step of nearly $\pi$ for grazing incidence. This means that the real component of $\underline{k}_{x}$ is approximately [55]

$$
k_{x}=\frac{\pi}{L_{x}}\left(n_{x}+\frac{1}{2}\right)
$$

where $n_{x}$ is an integer $0,1,2 \ldots$ 
Equations (A2) and (A3) gives

$$
\cos (\theta)=\frac{c \pi}{\omega L_{x}}\left(n_{x}+\frac{1}{2}\right)
$$

$\theta_{g}$ is defined by Equation (A4) for $n_{x}=0$. Thus we get

$$
\theta_{g}=\arccos \left(\frac{c}{4 f L_{x}}\right)
$$

By knowing the impedance $Z$ of the ceiling absorber, the grazing absorption coefficient $\alpha_{g}$ is then calculated as the average absorption coefficient in the grazing region defined by $\theta_{g}$.

\section{Appendix B}

Grazing absorption at low frequencies.

If we consider sound propagation mainly in the $y z$-plan in Figure A1, the surfaces at $x=0$ and $x=L_{x}$ are exposed for the grazing sound field. An expression for a grazing decay constant at low frequencies was derived by Morse and Bolt [71]. An expression of the decay constant at low frequencies is given by

$$
\delta=\rho c^{2}\left(\frac{A_{x 0}^{\prime}+A_{x l}^{\prime}}{2 l_{x}}+\frac{A_{y 0}^{\prime}+A_{y l}^{\prime}}{l_{y}}+\frac{A_{z o}^{\prime}+A_{z l}^{\prime}}{l_{z}}\right)
$$

where $A^{\prime}$ is the real part of the admittance. Assuming all the walls and floor in Figure A1 rigid, except for the ceiling, we get

$$
\delta=\rho c^{2} \frac{A_{x l}^{\prime}}{2 l_{x}}
$$

For the almost two-dimensional grazing sound field, the contribution from the ceiling to the grazing absorption is given by [55].

$$
\eta_{g, \text { ceiling }}=\frac{c}{\pi V \omega} S_{\text {ceiling }} \alpha_{g, \text { ceiling }}
$$

The relation between the loss factor $\eta$ and the decay constant $\delta$ is

$$
\eta=\frac{2 \delta}{\omega}
$$

The grazing ceiling absorption is given by combining Equations (A7)-(A9). We get

$$
\alpha_{g, \text { ceiling }}=\pi \rho c A_{x l}^{\prime}
$$

where $A_{x l}^{\prime}$ is the real part of the admittance for the ceiling absorber. $A_{x l}^{\prime}$ is given by real part of $1 / Z$ where $Z$ is given by Equation (22), assuming an extended reaction.

Equation (A10) is used as an approximation for $\alpha_{g, c e i l i n g}$ for the frequencies $125 \mathrm{~Hz}$ and $250 \mathrm{~Hz}$.

\section{References}

1. ISO. ISO 3382-1: 2009, Acoustics—Measurement of Room Acoustic Parameters_Part 1: Performance Spaces; ISO: Geneva, Switzerland, 2009.

2. ISO. ISO 3382-2: 2008, Acoustics-Measurement of Room Acoustic Parameters_Part 2: Reverberation Time in Ordinary Rooms; ISO: Geneva, Switzerland, 2008.

3. Astolfi, A.; Pellerey, F. Subjective and objective assessment of acoustical and overall environmental quality in secondary school clas srooms. J. Acoust. Soc. Am. 2008, 123, 163-173. [CrossRef] [PubMed]

4. Shield, B.; Conetta, R.; Dockrell, J.; Connolly, D.; Cox, T.; Mydlarz, C. A survey of acoustic conditions and noise levels in secondary school classrooms in England. J. Acoust. Soc. Am. 2015, 137, 177-188. [CrossRef] 
5. Shield, B.M.; Dockrell, J. The effects of environmentaland classroom noise on the academic attainments of primary school children. J. Acoust. Soc. Am. 2008, 123, 133-144. [CrossRef] [PubMed]

6. Shield, B.M.; Dockrell, J. The effects of noise on children at school: A review. J. Build. Acoust. 2003, 10, 97-116. [CrossRef]

7. Ljung, R.; Israelsson, K.; Hygge, S. Speech Intelligibility and Recall of Spoken Material Heard at Different Sig-nal-to-noise Ratios and the Role Played by Working Memory Capacity. Appl. Cogn. Psychol. 2013, 27, 198-203. [CrossRef]

8. Yang, W.; Bradley, J.S. Effects of room acoustics on the intelligibility of speech in classrooms for young children. J. Acoust. Soc. Am. 2009, 125, 922-933. [CrossRef] [PubMed]

9. Bradley, J.S.; Sato, H. The intelligibility of speech in elementary school classrooms. J. Acoust. Soc. Am. 2008, 123, 2078-2086. [CrossRef]

10. Oberdörster, M.; Tiesler, G. Akustiche Ergonomie der Schule, Schriftenreihe der Bundesanstalt fur Arbeitsschutz und Arbeitsmedizin, Forshung Fb1071; Universität Bremen: Bremen, Germany, 2006.

11. Sato, H.; Bradley, J.S. Evaluation of acoustical conditions for speech communication in working elementary school classrooms. J. Acoust. Soc. Am. 2008, 123, 2064-2077. [CrossRef]

12. Lyberg-Åhlander, V.; Rydell, R.; Löfqvist, A. Speaker's comfort in teaching environments: Voice problems in Swedish teaching staff. J. Voice 2011, 25, 430-440. [CrossRef]

13. Pelegrin-Garcia, D.; Brunskog, J.; Lyberg-Åhlander, V.; Löfqvist, A. Measurement and prediction of voice supportand room gain in school classrooms. J. Acoust. Soc. Am. 2012, 131, 194-204. [CrossRef] [PubMed]

14. Pelegrin-Garcia, D. Speakers' comfort and voicelevel variationin classrooms: Laboratory research. J. Acoust. Soc. Am. 2012, 132, 249-260. [CrossRef]

15. Bistrup, M. Health Effects of Noise on Children and the Perception of the Risk of Noise; National Institute of Public Health: Cpenhagen, Denmark, 2001.

16. Bistrup, M. Children and Noise-Prevention of Adverse Effects; National Institute of Public Health: Cpenhagen, Denmark, 2002.

17. Waye, K.P.; Fredriksson, S.; Hussain-Alkhateeb, L.; Gustafsson, J.; Van Kamp, I. Preschool teachers' perspective on how high noise levels at preschool affect children's behavior. PLoS ONE 2019, 14, e0214464. [CrossRef]

18. Ryherd, E.E.; Persson Waye, K.; Ljungkvist, L. Characterizing noise and perceived work environment in a neurological intensive care unit. J. Acoust. Soc. Am. 2008, 123, 747-756. [CrossRef]

19. Haapakangas, A.; Hongisto, V.; Eerola, M.; Kuusisto, T. Distraction distance and disturbance by noise-An analysis of 21 open-plan offices. J. Acoust. Soc. Am. 2017, 141, 127-136. [CrossRef]

20. ISO. ISO 3382-3:2012 Acoustics—Measurement of Room Acoustic Parameters_Part 3: Open Plan offices; ISO: Geneva, Switzerland, 2012.

21. ISO. ISO 22955:2021 Acoustics-Acoustic Quality of Open Office Spaces; ISO: Geneva, Switzerland, 2021.

22. Bradley, J. Review of objective room acoustics measures and future needs. Appl. Acoust. 2011, 72, 713-720. [CrossRef]

23. Sato, H.; Morimoto, M.; Sato, H.; Wada, M. Relationship between listening difficulty and acoustical objective measures in reverberant fields. J. Acoust. Soc. Am. 2008, 123, 2087-2093. [CrossRef]

24. Harvie-Clark, J.; Dobinson, N.; Hinton, R. Acoustic Response in Non-Diffuse Rooms. In Proceedings of the Euronoise, Prague, Czech Republic, 10-13 June 2012.

25. Rindel, J.H. Acoustical capacity as a means of noise control in eating establishment. In Proceedings of the Joint Baltic Nordic Acoustics Meeting, Odense, Denmark, 18-20 June 2012.

26. Nijs, L.; Rychtáriková, M. Calculating the optimum reverberation time and absorption coefficient for good speech intelligibility in classroom design using U50. Acta Acust. United Acust. 2011, 97, 93-102. [CrossRef]

27. Barron, M.; Lee, L.J. Energy relations in concert auditoriums. I. J. Acoust. Soc. Am. 1988, 84, 618-628. [CrossRef]

28. Barron, M. Theory and measurement of early, late and total sound levels in rooms. J. Acoust. Soc. Am. 2015, 137, 3087-3098. [CrossRef] [PubMed]

29. Nilsson, E. Input data for acoustical design calculations for ordinary public rooms. In Proceedings of the 24th International Congress on Sound and Vibration, London, UK, 23-27 July 2017.

30. Sabine, W.C. Collected Papers on Acoustics; Dover Publications: New York, NY, USA, 1964.

31. Rasmussen, B.; Brunskog, J.; Hoffmeyer, D. Reverberation time in class rooms-Comparison of regulations and classi-fication criteria in the Nordic countries. In Proceedings of the Joint Baltic-Nordic Acoustics Meeting, Odense, Denmark, 18-20 June 2012.

32. IEC. IEC 60268-16 Sound System Equipment_Part 16: Objective Rating of Speech Intelligibility by Speech Transmission Index; IEC: Geneva, Switzerland, 2011.

33. Astolfi, A.; Parati, L.; D'Orazio, D.; Garai, M. The new Italien standard UNI 11532 on acoustics for schools. In Proceedings of the 23rd International Congress on Acoustics, Aachen, Germany, 9-13 September 2019.

34. Cremer, L.; Muller, H.A.; Schultz, T.J. Principles and Applications of Room Acoustics Vol 1; Applied Science Publishers: London, UK, 1982.

35. Kuttruff, H. Room Acoustics, 3rd ed.; Elsevier Science Publishers Ltd.: London, UK, 1991.

36. Joyce, W.B. Sabine's reverberation time and ergodic auditoriums. J. Acoust. Soc. Am. 1975, 58, 643-655. [CrossRef]

37. Joyce, W.B. Exact effect of surface roughness on the reverberation time of a uniformly absorbing spherical enclosure. J. Acoust. Soc. Am. 1978, 64, 1429-1436. [CrossRef]

38. Fitzroy, D. Reverberation formulae which seem to be more accurate with non-uniform distribution of absorption. J. Acoust. Soc. Am. 1959, 31, 893-897. [CrossRef] 
39. Neubauer, N.O. Estimation of reverberation time in rectangular rooms with non-uniformly distributed absorption using a modified Fitzroy equation. Build. Acoust. 2001, 8, 115-137. [CrossRef]

40. Arau-Puchades, H. An improved reverberation formula. Acustica 1988, 65, 163-180.

41. Cucharero, J.; Hänninen, T.; Lokki, T. Influence of sound-absorbing material placement on room acoustical parame-ters. Acoustics 2019, 1, 644-660.

42. Sakuma, T. Approximate theory of reverberation in rectangular rooms with specular and diffuse reflections. J. Acoust. Soc. Am. 2012, 132, 2325-2336. [CrossRef] [PubMed]

43. Bistafa, S.R.; Bradley, J.S. Predicting reverberation times in a simulated classroom. J. Acoust. Soc. Am. 2000, 108, 1721-1731. [CrossRef]

44. Prodi, N.; Visentin, C. An experimental evaluation of the impact of scattering on sound field diffusivity. J. Acoust. Soc. Am. 2013, 133, 810-820. [CrossRef] [PubMed]

45. ISO. ISO 354:2003 Acoustics-Measurement of Sound Absorption in a Reverberation Room; ISO: Geneva, Switzerland, 2003.

46. Nolan, M.; Berzborn, M.; Fernandez-Grande, E. Isotropy in decaying reverberant sound fields. J. Acoust. Soc. Am. 2020, 148, 1077-1088. [CrossRef]

47. Nilsson, E. Decay Processes in Rooms with Non-Diffuse Sound Fields Part I: Ceiling Treatment with Absorbing Material. Build. Acoust. 2004, 11, 39-60. [CrossRef]

48. Nilsson, E. Decay processes in rooms with non-diffuse sound fields-Part II: Effect of irregularities. Build. Acoust. 2004, 11, 133-143. [CrossRef]

49. EN 12354-6:2004, Building Acoustics-Estimation of Acoustic Performance of Buildings from the Performance of Elements-Part 6: Sound Absorption in Enclosed Spaces; CEN: Brussels, Belgium, 2004.

50. Lochner, J.; Burger, J. The influence of reflections on auditorium acoustics. J. Sound Vib. 1964, 1, 426-454. [CrossRef]

51. Visentin, C.; Pellegatti, M.; Prodi, N. Effect of a single lateral diffuse reflection on spatial percepts and speech intelligi-bility. J. Acoust. Soc. Am. 2020, 148, 122-140. [CrossRef]

52. Bradley, J.S.; Sato, H.; Picard, M. On the importance of early reflections for speech in rooms. J. Acoust. Soc. Am. 2003, 113, 3233-3244. [CrossRef]

53. Lyon, R.H.; De Jong, R.G. Theory and Application of Statistical Energy Analysis, 2nd ed.; RH Lyon Corp: Cambridge, MA, USA, 1998; p. 02138.

54. Crighton, D.G.; Dowling, A.P.; Ffowcs Williams, J.E.; Heckl, M.; Leppington, F.G. Modern Methods in Analytical Acoustics; Springer London: London, UK, 1992; Chapter 8.

55. Nilsson, E. Decay Processes in Rooms with Non-Diffuse Sound Fields; Report TVBA-1004; Engineering Acoustics, LTH, Lund University: Lund, Sverige, 1992.

56. Barron, M.; Barron, M. Growth and decay of sound intensity in rooms according to some formulae of geometric acoustics theory. J. Sound Vib. 1973, 27, 183-196. [CrossRef]

57. Available online: https:/ / alphacell.matelys.com/ (accessed on 16 July 2021).

58. Available online: https:// norsonic.se/product_single/norflag/ (accessed on 16 July 2021).

59. Miki, Y. Acoustical properties of porous materials. Modifications of Delany-Bazley models. J. Acoust. Soc. Jpn. (E) 1990, 11, 19-24. [CrossRef]

60. Jeong, C.-H. Guidline for adopting the local reaction assumption for porous absorbers in terms of random incidence ab-sorption coefficients. Acta Acoust. United Acust. 2011, 97, 779-790. [CrossRef]

61. Delany, M.; Bazley, E. Acoustical properties of fibrous absorbent materials. Appl. Acoust. 1970, 3, 105-116. [CrossRef]

62. Komatsu, T. Improvement of the Delaney-Bazley and Miki models for fibrous sound-absorbing materials. Acoust. Sci. Tech. 2008, 29, 121-129. [CrossRef]

63. Paris, E.T. On the coefficient of sound-absorption measured by the reverberation method. Philos. Mag. 1928, 5, 489. [CrossRef]

64. Bakoulas, K. Optimization of an Energy-Based Room Acoustics Model that Considers Scattering and Non-Uniform Absorption. Master's Thesis, Department of Electrical Engineering, Technical University of Denmark, Lyngby, Denmark, 2017.

65. Nilsson, E. Sound scattering in rooms with ceiling treatment. In Nordtest Technical Report TR 606; Nordic Innovation Centre: Oslo, Norway, 2007.

66. ISO. ISO 11654:1997 Acoustics—Sound Absorbers for Use in Buildings_Rating of Sound Absorption; ISO: Geneva, Switzerland, 1997.

67. Arvidsson, E.; Nilsson, E.; Hagberg, D.B.; Karlsson, O.J.I. The effect on room acoustical parameters using a combina-tions of absorbers and diffusors-An experimental study in a classroom. Acoustics 2020, 2, 505-523. [CrossRef]

68. Marbjerg, G.; Brunskog, J.; Jeong, C.-H.; Nilsson, E. Development and validation of a combined phased acoustical radi-osity and image source model for predicting sound fields in rooms. J. Acoust. Soc. Am. 2015, 138, 1457-1468. [CrossRef] [PubMed]

69. Pind, F.; Jeong, C.-H.; Engsig-Karup, A.P.; Hesthaven, J.S.; Stromann-Andersen, J. Time-domain room acoustic simula-tions with extended-reacting porous absorbers using the discontinuous Galerkin method. J. Acoust. Soc. Am. 2020, 148, 2851-2863. [CrossRef] [PubMed]

70. Cremer, L.; Muller, H.A.; Shultz, T.J. Principles and Applications of Room Acoustics Vol 2; Applied Science Publishers: London, UK, 1982.

71. Morse, P.M.; Bolt, R.H. Sound waves in rooms. Rev. Mod. Phys. 1944, 16, 69-150. [CrossRef] 